\title{
SATISFACCIÓN DE LOS SECRETARIOS DE CENTROS EDUCATIVOS
}

\section{(Secretaries of educational centers' satisfaction)}

por

\section{$\underline{\text { Article record }}$ \\ $\underline{\text { About authors }}$ \\ $\underline{\text { HTML format }}$}

\author{
Juan Caballero Martínez ( jcaballe@ugr.es) \\ Carmen R. Fernández Camacho (crfernandez@us.es) \\ Eduardo García Jiménez (egarji@us.es )
}

$\underline{\text { Ficha del artículo }}$
$\underline{\text { Sobre los autores }}$
$\underline{\text { Formato HTML }}$

\begin{abstract}
The primary target to study in this article is the level of satisfaction of the secretaries who exercise their professional activities in the Region of Andalusia. The article is structured in two very defined parts. The first part is a review of the written material relevant to the level of satisfaction in the labor and educative atmosphere, as well as the current situations the administration of the public school are going through and the consequences derived from the application of the different laws, specifically the LODE, LOPEGCD and LOCE.

The second part presents the research in itself. The experimental design is described, in which different methodologic options are combined: descriptive and comparative. Through these options, the level of satisfaction of the secretaries in the non-university centers is studied and in the following dimensions that were selected: firstly, professional accomplishment, personal relations and organizational structure of the center; and secondly, the relations and differences between the demographic variables and the level of satisfaction.
\end{abstract}

\section{Keywords}

Secretaries, satisfaction, organization of educational centers

\section{Resumen}

Con este trabajo pretendemos estudiar el nivel de satisfacción de los Secretarios de los Centros Educativos de la Comunidad Autónoma Andaluza. Este artículo se estructura en dos partes muy delimitadas: En la primera, se hace una revisión de la literatura sobre la satisfacción en el ámbito laboral y educativo, así como la situación actual por la que atraviesa la dirección de los centros escolares públicos y las consecuencias derivadas de la aplicación de las distintas leyes, especialmente la Ley Orgánica de Derecho a la Educación (LODE), la Ley Orgánica de Participación, la Evaluación y el Gobierno de los Centros Docentes (LOPEGCD) y la Ley Orgánica de Calidad de la Educación (LOCE).

En la segunda parte se recoge la investigación propiamente dicha. Se describe el diseño de investigación, en el que se combinan distintas opciones metodológicas: descriptivas y comparativas. Por medio de ellas se intenta detectar el nivel de satisfacción de los Secretarios en los centros no universitarios en cada una de las dimensiones que se han seleccionado (realización profesional, relaciones personales y estructura organizativa del centro) y las relaciones y diferencias entre las variables demográficas y el nivel de satisfacción

\section{Descriptores}

Secretarios, satisfacción, organización de centros educativos 


\section{Contexto Sociopolítico}

En este artículo se presenta una investigación cuyo objetivo principal fue conocer el nivel de satisfacción de los Secretarios que ejercen sus funciones en la Comunidad Autónoma de Andalucía.

La Dirección en las Instituciones Educativas es un tema de candente actualidad en estos últimos años, al ser considerado por la Ley Orgánica General del Sistema Educativo (LOGSE) (1990) como uno de los factores claves para la mejora de la calidad de la enseñanza en los Centros Educativos.

Como fruto de este interés creciente han aparecido numerosas publicaciones específicas sobre el tema y se han celebrado diversos encuentros científicos, entre los cuales se destacan los siguientes: seis Congresos Interuniversitarios de Organización Escolar (1990, 1992, 1994, 1996, 1998 y 2000); tres Congresos internacionales sobre Dirección Escolar organizados por el ICE de la Universidad de Deusto (1992, 1998 y 2000); tres Jornadas del Fórum Europeo de Administradores de la Educación (1991, 1993 y 1996); un Seminario sobre Dirección de Centros Escolares organizado por el Consejo Escolar de Estado (1993); seis Jornadas Andaluzas sobre Organización y Dirección de Instituciones Educativas (1996 al 2001).

Este notable desarrollo teórico contrasta con la situación de crisis de la Dirección que se vive en los Centros Educativos y cuya manifestación más patente queda reflejada en las estadísticas anuales del Consejo Escolar de Estado, que en sus diversos informes recoge el dato alarmante de que muchos Directivos no son elegidos por el Consejo Escolar, por falta de candidatos, y las consecuencias negativas que se derivan de esta situación, tanto para los Centros como para los candidatos, quienes, sin haber mostrado ningún deseo de ser Directivos, son nombrados, en algunos casos en contra de su voluntad, por la Administración Educativa por un periodo de un año, a partir de la promulgación de la Ley Orgánica de Derecho a la Educación (LODE) (1985), cuatro años, desde la entrada en vigor de la LOPEGCD (1995) y tres años con la LOCE (2002). También se denuncia reiteradamente el problema que afecta a la Dirección Escolar. Baste por ejemplo un párrafo:

"La Enseñanza Pública ha visto descender notablemente el número de candidatos y candidatas a las elecciones a Directores y Directoras de los Centros Públicos. Esta preocupación ya ha sido manifestada en los informes correspondientes a cursos anteriores, por lo que parece pertinente señalar la necesidad de promover un debate serio y riguroso en los Centros Educativos, con plazos y ritmos adecuados para obtener un diagnostico fiable sobre las razones que expliquen estas conductas de inhibición del profesorado.

En relación con ello el Consejo Escolar de Estado (...) urge para que el Ministerio modifique la normativa legal vigente, a fin de que pueda avanzarse en la solución de este problema, que pasa por una decidida potenciación de la figura del Director y de su dimensión personal" (Consejo Escolar del Estado, 1994: 36-37).

Esta situación de crisis se agudiza con la promulgación de la Ley Orgánica de Derecho a la Educación (LODE) (1985), que apuesta por un modelo de dirección participativo, puesto que nace en un momento de transición de la vida política y social española. En efecto, el paso de un sistema político autoritario a un sistema democrático impulsa un modelo de gestión escolar al estilo del sistema político, introduciendo los principios democráticos del parlamento, la participación universal y los procesos electorales. Todo esto ha propiciado "la creación de un tipo de gestión y de Dirección Escolar de los Centros Públicos basado más en poner un énfasis especial en fomentar y garantizar procesos participativos que en tratar de conseguir otros resultados educativos o en pro- 
Caballero Martínez, J., Fernández Camacho, C.R. y García Jiménez, E. (2003). Satisfacción de los secretarios de centros educativos. RELIEVE, v. 9, n. 2, p. 198-235.

http://www.uv.es/RELIEVE/v9n2/RELIEVEv9n2 7.htm

curar una acción directiva basada en la competencia, la capacitación y la estabilidad" (Antúnez, 1993: 175).

Cantón (1996) ha sintetizado los problemas de este modelo de Dirección, analizados por varios autores (Álvarez, 1992; Hanson y Ul- rich, 1992; Lorenzo, 1994; Immegart e Immegart, 1995; Sáenz y Debón, 1995, 1997; Gairín, 1995; Villa y Villardón, 1998; Muri11 y Pérez, 1998) y los ha clasificado en dos categorías (endógenos y exógenos), a los que ha añadido los contextuales.

\begin{tabular}{|l|l|}
\hline FACTORES ENDÓGENOS & FACTORES EXÓGENOS Y CONTEXTUALES \\
\hline El propio funcionamiento de la dirección & Factores exógenos \\
Existencia de radicales y descontentos & Poco apoyo de la Administración \\
Deficiente preparación & Conflicto de padres con el C. Escolar \\
Inestabilidad en el cargo & Colisión intereses administración y centro \\
La endogamia & Poco apoyo de los profesores \\
Falta de incentivos profesionales & Escasa colaboración de padres \\
Desinterés colectivo & Problemas familiares \\
Celularismo de los profesores & Especificidad por el género de la dirección \\
Ambigüedad de funciones y representación & La vuelta al mismo claustro \\
Conflictividad entre compañeros & \\
Tensión y estrés & Factores contextuales \\
Excesivas y complicadas tareas & Específicos de cada centro y lugar \\
Falta de autonomía para tomar decisiones & Padres entrometidos, pasotas, dirigentes \\
importantes & Alumnado y promociones problemáticas \\
& Falta de colaboración de la comunidad \\
& Falta de hábitos y compromiso con el centro \\
& Otros (dependiendo de cada caso) \\
\hline
\end{tabular}

Cuadro 1. Factores endógenos y exógenos de la crisis de la Dirección.

Con la aprobación en 1995 de la Ley Orgánica de la Participación, la Evaluación y el Gobierno de los Centros Docentes (LOPEGCD) se pretende conseguir tres objetivos: la mejora de la calidad de la enseñanza, la necesidad de adaptar la organización de los centros a la Ley Orgánica General del Sistema Educativo (LOGSE) y resolver las dificultades detectadas en el modelo de dirección de la Ley Orgánica de Derecho a la Educación (LODE). Por tanto, la Ley Orgánica de Participación, la Evaluación y el Gobierno de los Centros Docentes (LOPEGCD) completa el marco legal desarrollado en la LOGSE y en la Ley Orgánica de Derecho a la Educación (LODE), en lo que a Organización de los Centros Educativos se refiere.

La LOPEGCD pretende impulsar la calidad de la enseñanza, proporcionando un marco legal en el que sea posible una mayor autonomía de los Centros Educativos, garan- tizando una mejor formación de los Equipos Directivos y una mayor participación de la Comunidad Educativa en la vida del Centro. Con las medidas relevantes, relacionadas con el ejercicio de la Dirección, se intenta potenciar la participación de la Comunidad Educativa y, además, el control social de la educación, mediante la elección del Director por el Consejo Escolar, y hacer posible que los profesores mejor preparados accedan a la Dirección.

Por último, la LOCE deroga, entre otros Títulos, el dos de la LOPEGCD que hace referencia a los Órganos de Gobierno de los Centros Docentes Públicos e introduce cambios sustanciales, como por ejemplo: el Consejo Escolar y el Claustro de Profesores dejan de ser órganos de gobierno y pasan a ser órganos de participación en el control y gestión de los centros. El Director es objeto de un tratamiento específico, especialmente en 
lo que se refiere al procedimiento para su selección y nombramiento que se efectuará mediante concurso de méritos por una Comisión constituida por representantes de la Administración Educativa y, al menos, en un treinta por ciento por representantes del centro correspondiente.

\section{Contexto Conceptual}

La satisfacción en el trabajo ocupa en la actualidad uno de los lugares más relevantes en la Psicología del Trabajo y de las Organizaciones; existe un gran interés por comprender el fenómeno de la satisfacción o de la insatisfacción en el trabajo; sin embargo resulta paradójico que, a pesar de esta espectacular proliferación de literatura científica sobre la satisfacción en el trabajo, no puede hablarse, en cambio, de un progreso paralelo en las investigaciones; los avances conseguidos resultan poco gratificantes y significativos.

Sin embargo la satisfacción en el trabajo se viene situando en los últimos años como uno de los temas de especial interés en el ámbito de la investigación. Para Weinert (1985: 2978) son varias las razones que tienen relación con el desarrollo histórico de las Teorías de la Organización, las cuales han experimentado cambios a lo largo del tiempo. Dicho autor propone las siguientes:

a) Posible relación directa entre la productividad y la satisfacción del trabajo.

b) Posibilidad y demostración de la relación negativa entre la satisfacción y las pérdidas horarias.

c) Relación posible entre satisfacción y clima organizativo.

d) Creciente sensibilidad de la dirección de la organización sobre la importancia de las actitudes y de los sentimientos de los colaboradores en relación con el trabajo, el estilo de dirección, los superiores y toda la organización.

e) Importancia creciente de la información sobre las actitudes, las ideas de valor y los objetivos de los colaboradores en relación con el trabajo del personal.

f) Ponderación creciente de la calidad de vida en el trabajo como parte de la calidad de vida. La satisfacción en el trabajo influye poderosamente sobre la satisfacción en la vida cotidiana.

El propio autor destaca cómo en el conjunto de las organizaciones aspectos psicológicos tan importantes como las reacciones afectivas y cognitivas despiertan en el seno de las mismas niveles de satisfacción e insatisfacción en el trabajo.

Robbins y Coulter (1996: 181) coinciden con Weinert a la hora de definir la satisfacción en el puesto, centrándose básicamente, al igual que el anterior, en los niveles de satisfacción e insatisfacción sobre la proyección actitudinal de positivismo o negativismo y definiéndola "como la actitud general de un individuo hacia su trabajo. Una persona con un alto nivel de satisfacción en el puesto tiene actitudes positivas hacia el mismo; una persona que está insatisfecha con su puesto tiene actitudes negativas hacia él”.

Conviene también destacar que el puesto de una persona es más que las actividades obvias de manejar papeles, esperar a clientes o manejar un camión. Los puestos requieren de la interacción con compañeros de trabajo y jefes, el cumplimiento de reglas y políticas organizacionales, la satisfacción de las normas de desempeño, el aceptar condiciones de trabajo que frecuentemente son menos que ideales, y cosas similares.

Muñoz Adanez (1990: 76) define la satisfacción laboral como "el sentimiento de agrado o positivo que experimenta un sujeto por el hecho de realizar un trabajo que le interesa, en un ambiente que le permite estar a gusto, dentro del ámbito de una empresa u organización que le resulta atractiva y por el que percibe una serie de compensaciones psico-socio-económicas acordes con sus expectativas". Del mismo modo, define la insatisfacción laboral como "el sentimiento 
de desagrado o negativo que experimenta un sujeto por el hecho de realizar un trabajo que no le interesa, en un ambiente en el que está a disgusto, dentro del ámbito de una empresa u organización que no le resulta atractiva y por el que recibe una serie de compensaciones psico-socio-económicas no acordes con sus expectativas".

Loitegui (1990: 83) utiliza con mayor frecuencia en su trabajo los siguientes conceptos: motivos, actitudes, moral laboral, satisfacción laboral. Para este autor, la satisfacción laboral es un constructo pluridimensional, que depende tanto de las características individuales del sujeto cuanto de las características y especificidades del trabajo que realiza. Además, el concepto de satisfacción en el trabajo está integrado por un conjunto de satisfacciones específicas, o aspectos parciales, que determinan la satisfacción general.

Las facetas del trabajo, en cuanto a su incidencia en la satisfacción laboral de los trabajadores, que ha tratado son: funcionamiento y eficacia en la organización, condiciones físico-ambientales del trabajo, contenido interno del trabajo, grado de autonomía en el trabajo, tiempo libre, ingresos económicos, posibilidades de formación, posibilidades de promoción, reconocimiento por el trabajo, relaciones con los jefes, relaciones de colaboración y trabajo en equipo y prestaciones sociales.

Concluye diciendo que la satisfacción laboral depende de la interacción entre dos clases de variables: a) Los resultados que consigue el trabajador mediante la realización del propio trabajo. b) Cómo se perciben $\mathrm{y}$ vivencian dichos resultados en función de las características y peculiaridades de la personalidad del trabajador.

Por último, para Kreitner y Kinicki (1997: 171) la satisfacción laboral "es una respuesta afectiva o emocional hacia varias facetas del trabajo del individuo". Esta definición no recoge una conceptualización uniforme $\mathrm{y}$ estática, ya que la propia satisfacción laboral puede proyectarse desde un aspecto determinado, produciendo satisfacción en áreas concretas de ese trabajo e insatisfacción en otras facetas que este mismo trabajo exija para su desempeño.

Para finalizar, y atendiendo a las aportaciones de los diferentes autores, diremos que la satisfacción laboral nace en el contexto laboral, desde la implicación de los distintos aspectos que de una forma $u$ otra influyen en el estado de ánimo y situación emocional de la persona, proyectándose desde aquí situaciones y perspectivas positivas o negativas, según los agentes implicados en el quehacer laboral.

\subsection{Concepto de satisfacción en la ense- ñanza}

Las Ciencias de la Educación han tratado también la satisfacción/insatisfacción de los docentes, utilizando una gran variedad de términos como "el malestar docente", "angustia de los enseñantes", "conflicto de los profesores", "estrés y ansiedad del profesorado", "el burnout (estar quemado) docente", "la salud mental del profesorado", "el retraimiento", etc. Todos estos términos hacen referencia a aspectos que se han venido estudiando e investigando sobre la satisfacción e insatisfacción de los docentes, que cuentan con cierta experiencia en la educación.

Para Padrón (1995: 4) la satisfacción personal y profesional está estrechamente relacionada con la salud mental y el equilibrio personal. En el caso del profesorado, la satisfacción tiene que ver con las situaciones específicas de su labor docente y con las características de su propia personalidad, en cuanto que todo ello repercute en su estabilidad emocional, creando tensión, estrés, y produciendo malestar, tanto desde una perspectiva personal como profesional. La personalidad no es un "ente" abstracto sino que se hace presente y se realiza en la interacción con el medio. En estas relaciones cada persona va a 
adquirir su propio ajuste o adaptación, tanto personal como social.

Para este mismo autor la satisfacción se puede entender desde dos perspectivas:

a) Perspectiva personal. En este sentido, la satisfacción viene determinada por el propio trabajo que realiza el individuo, cuando se proyecta directamente de forma gratificante hacia las necesidades del propio sujeto, a la vez, que, se hace extensivo de forma genérica a las distintas facetas de la persona.

b) Perspectiva profesional. Desde este enfoque, van a ser las relaciones personales, tanto en el centro del trabajo como en el entorno, las que determinen la satisfacción/insatisfacción del individuo.

Por tanto, la satisfacción no es sólo expresión de una vivencia subjetiva. El trabajador, al vivir la experiencia de autoeficacia personal, se siente profesionalmente satisfecho.

La ambivalencia del concepto satisfacción se manifiesta en una diversidad de usos: como estado emocional, como actitud, como motivación, como rasgo de personalidad. Gordillo (1988: 260) realizó una revisión de estos significados en diferentes autores.

Brüggemann (citado por Padrón, 1995) adopta una concepción pluridimensional de la satisfacción profesional. Para este autor, $\boldsymbol{l a}$ satisfacción profesional "es el resultado de una comparación entre lo que hace y lo que debería de hacer: a medida que la distancia disminuye, la satisfacción aumenta".

Este enfoque es integral, en el sentido de considerar a la personalidad desde el conjunto de sus dimensiones básicas o ámbitos: cognitivo, afectivo y conativo o conductual. Optamos por considerar la satisfacción como una actitud o variable personal integradora en la que la conducta del sujeto es resultado del acuerdo y expresión armónica entres su pensamiento y sus sentimientos, produciendo así una reacción orgánica de equilibrio y de bienestar, traducida, por tanto, no sólo en su salud corporal sino también mental (Padrón, 1995; Gordillo, 1988). Se acercan, así, a la definición actitudinal de la satisfacción laboral como el conjunto de reacciones, sentimientos y sensaciones de un miembro de la organización laboral frente a su trabajo.

Zubieta y Susinos (1992: 13) eluden definir la satisfacción, pero señalan, a partir de las aportaciones de Lucas Marín, unas conclusiones sobre la satisfacción en el trabajo:

- "La satisfacción es una función del grado en que las necesidades personales del individuo están cubiertas en la situación laboral" (Teoría de las necesidades sociales).

- "La satisfacción laboral es función del grado en que las características del puesto de trabajo se ajustan a las normas y deseos de los grupos que el individuo considera como guía para su evolución del mundo y para su definición de la realidad social" (Teoría del grupo de referencia social).

Estos autores establecen, además, una distinción entre las variables que influyen en el nivel de satisfacción:

a) Variables ambientales que influyen en el nivel de satisfacción:

- Cuanto más elevado sea el nivel profesional mayor es la satisfacción.

- A mayor variación en la actividad mayor satisfacción.

- El liderazgo más participativo produce una mayor satisfacción laboral.

- El salario y la promoción laboral correlacionan positivamente con la satisfacción.

- La aceptación en el grupo de trabajo produce satisfacción.

b) Variables personales que influyen en la satisfacción:

- No existen datos que indiquen variación en la satisfacción según el sexo del trabajador. 
- Dentro del mismo nivel profesional, a mayor nivel educativo menos satisfacción.

- La satisfacción se incrementa con la edad, hasta pocos años antes de la jubilación.

Para González Tirados, citado por Saénz y otros (1993) el concepto de satisfacción aparece ligado al clima de una organización, entendido como el conjunto de estímulos, motivaciones $\mathrm{y}$ factores que el individuo percibe como característicos de su lugar de trabajo. Las actitudes, los sentimientos, las vivencias profundas $\mathrm{y}$, sobre todo, las reacciones afectivas con que el sujeto se relaciona con el clima organizativo que percibe constituyen la base de su satisfacción profesional. No es, pues, a través del mundo de la fría racionalidad como se puede conocer y penetrar en el ámbito de la satisfacción en el trabajo de los enseñantes.

Sáenz y Otros definimos la satisfacción del profesorado universitario "como una experiencia gozosa de crecimiento psicológico, producida por el logro de niveles cada vez más altos en la calidad de su trabajo, de reconocimiento por lo que hace, de responsabilidad, de creación del saber, de libertad cientifica, de disfrute en el trabajo mismo" (Sáenz y otros, 1993: 22). Reconocemos en la satisfacción un carácter multidimensional, percibiendo un componente genérico o global más otros estados generados por factores bien identificados y bastantes comunes en la investigación sobre el tema. En un acercamiento simplificador, hemos definido la satisfacción general como un "estado espiritualmente gratificante".

\section{Diseño de la investigación}

Nuestro diseño de investigación comprende actuaciones típicamente descriptivas relacionadas con la identificación del nivel de satisfacción de los Secretarios. De igual modo, para profundizar en el conocimiento de dichos condicionantes intentaremos determinar las posibles diferencias existentes entre estos miembros del equipo directivo respecto a su satisfacción personal y profesional. En definitiva, el diseño de nuestra investigación combina distintas opciones metodológicas: descriptivas e inferenciales.

Respecto a las primeras, que intentan acercarse al nivel de satisfacción de los Secretarios de centros no universitarios, hemos ideado un instrumento de encuesta -un cuestionario- (Caballero: 2001) que intenta recoger sus opiniones sobre diferentes dimensiones y ámbitos relacionados con su labor profesional. En apartados que siguen a éste describiremos el modo en que se ha construido dicho instrumento e identificaremos los reactivos utilizados.

El estudio inferencial intenta averiguar si existen diferencias estadísticamente significativas entre las opiniones de los Secretarios (recogidas en las dimensiones y ámbitos del cuestionario) respecto a su satisfacción en el cargo.

\subsection{Recogida de la información}

El proceso de construcción del cuestionario se hizo con el fin de identificar todos los aspectos que se deberían incluir, además de una consulta exhaustiva de bibliografía y de investigaciones similares, se han mantenido varias entrevistas con Directores en ejercicio, expertos en el tema, antes de la primera redacción del cuestionario. Además, la selección de dimensiones del cuestionario se han contrastado con otros instrumentos que tienen que ver mucho con el tema de estudio. Dichos instrumentos fueron los siguientes:

a. "Cuestionario de satisfacción profesional docente" (Padrón Hernández, 1994) que comprende diez dimensiones:

1. Elección profesional

2. Interacción profesor-alumno

3. Relación con los compañeros y compañeras de trabajo

4. Relaciones con los padres y madres de mis alumnos y alumnas

5. Organización y funcionamiento de mi centro de trabajo 
Caballero Martínez, J., Fernández Camacho, C.R. y García Jiménez, E. (2003). Satisfacción de los secretarios de centros educativos. RELIEVE, v. 9, n. 2, p. 198-235.

http://www.uv.es/RELIEVE/v9n2/RELIEVEv9n2 7.htm

6. Relaciones con la Administración Educativa

7. Mi tarea como profesor o profesora

8. Estilo de enseñante

9. Formación y preparación profesional

10. Satisfacción general como profesor o profesora

Los objetivos fundamentales de esta investigación fueron: Conocer el nivel de insatisfacción profesional del profesorado que ejerce en la enseñanza no universitaria, en cada una de las dimensiones de su actividad docente, y comparar el nivel de insatisfacción profesional del profesorado de la enseñanza no universitaria con el nivel de insatisfacción profesional de otros trabajadores no docentes y que, por su nivel de cualificación, podrían ejercer también la profesión de enseñante.

b. "Los profesores evalúan la Universidad", cuestionario que se aplicó en la Universidad Complutense de Madrid, en abril y mayo de 1990, dirigido por Fernández, (1991) y que comprende seis ámbitos:

1. El grado de satisfacción ante las instituciones universitarias (M.E.C., Rectorado y Decanatos).

2. El clima social del profesorado (las relaciones con sus compañeros, fundamentalmente aquéllas que se mantienen dentro de cada Departamento.

3. Las relaciones alumnos/profesor desde la perspectiva de este último (dado que las opiniones de los alumnos sobre la docencia del profesor ya habían sido analizadas).

4. Los procesos actuales de selección y promoción del profesorado.

5. Un conjunto de elementos ponderativos de especial significación para la valoración de la productividad investigadora y la calidad docente (ratio alumnos/profesor, autopercepción del profesorado, etc.).

6. El funcionamiento de los principales servicios institucionales (biblioteca, laboratorio, secretaría, etc.).

El objetivo del estudio iba dirigido a posibilitar una mejora de la productividad inves- tigadora y docente del profesorado universitario.

c. "Cuestionario de satisfacción profesional para profesores" de $\mathrm{M}^{\mathrm{a}}$ Victoria Gordillo (1988), que comprende nueve ámbitos:

1. Dirección del Centro

2. Actividad

3. Retribución económica

4. Relación con padres

5. Estrés

6. Instalación escolar

7. Relaciones con colegas

8. Imagen social

9. Satisfacción general

Los objetivos de este estudio fueron describir la satisfacción/insatisfacción de los profesores, no sólo de un modo cuantitativo sino también cualitativo, deduciendo consecuencias prácticas que llevaran al desarrollo de situaciones profesionales en las que se facilitara el desarrollo personal, la mejora de las condiciones de trabajo y la relación con los alumnos.

d. "Cuestionario sobre condiciones de trabajo en la enseñanza pública no universitaria" (Federación de Enseñanza de ccoo 1993). Los ámbitos en los que se centró la investigación fueron:

1. Retribuciones

2. Jornada y calendario

3. Salud laboral

4. El trabajo docente y su evaluación

5. Formación del profesorado

6. Carrera docente y expectativas profesionales

7. Calidad de la enseñanza y Reforma del Sistema Educativo

8. Los sindicatos y el profesorado

Los objetivos generales de esta investigación fueron conocer los principales elementos de insatisfacción del profesorado respecto a sus condiciones profesionales y laborales, así como posibles alternativas de solución, todo ello desde su propia percepción, y ave- 
Caballero Martínez, J., Fernández Camacho, C.R. y García Jiménez, E. (2003). Satisfacción de los secretarios de centros educativos. RELIEVE, v. 9, n. 2, p. 198-235.

http://www.uv.es/RELIEVE/v9n2/RELIEVEv9n2 7.htm

riguar aspectos concretos de su realidad laboral.

\section{e. "Cuestionario sobre la función direc-} tiva: Problemas y formación" (De Vicente y Otros, 1996), utilizado en una investigación sobre los equipos directivos de los centros escolares de Andalucía. Comprende tres ámbitos:

\section{Datos previos}

2. Problemas de la función directiva actualmente

3. Inventario de creencias sobre formación de directivos

f. "Cuestionario C-3 Estudio de las necesidades de formación de los equipos directivos de los centros educativos", de Gairín (1995). Instrumento diseñado para la detección de necesidades formativas normativas, expresadas, percibidas y comparativas, con la finalidad de proponer modelos y currícula de formación aplicables a nuestra realidad.

g. "Cuestionario sobre el nivel de satisfacción del profesorado de la Universidad de Granada" de Sáenz y otros, (1993) que comprende seis ámbitos:

1. Docencia

2. Realización profesional

3. Relaciones personales

3.1. Con los alumnos

3.2. Con los profesores

4. Estructura organizativa

4.1. El Departamento

4.2. El Centro Docente

4.3. La Universidad de Granada como Organización

5. Perspectiva socio-laboral

6. Investigación

Teniendo en cuenta la revisión pedagógica existente sobre la Dirección en las investigaciones que anteriormente hemos mencionado, el cuestionario de la satisfacción de los Secretarios se ha diseñado a partir de tres dimensiones que son las siguientes:

\section{A. REALIZACIÓN PROFESIONAL}

\section{B. RELACIONES PERSONALES}

\section{ESTRUCTURA ORGANIZATIVA}

La dimensión Realización Profesional consta de 18 ítems y están referidos a la satisfacción/insatisfacción sobre la tensión que comporta su trabajo, el reconocimiento social que perciben, el complemento económico que reciben, la forma de acceder al cargo, las posibilidades de promoción profesional/académica, el tiempo que disponen para realizar sus tareas, las condiciones materiales en que realizan su trabajo y el nivel de logro alcanzado en su trabajo como Secretarios.

La siguiente dimensión, Relaciones Personales, ha sido estructurada en cuatro ámbitos que son: Interacción Secretarios - alumnos/as (9 ítems), Relaciones con los compañeros (10 ítems), Relaciones con los padres (11 ítems), Relación con la Administración educativa y municipal (10 ítems).

Finalmente, la dimensión Estructura Organizativa comprende, asimismo, cuatro ámbitos que son: El centro docente (11 ítems), Los equipos y departamentos/seminarios docentes (14 ítem), El Claustro de profesores (11 ítems), El Consejo Escolar (12 ítem).

Asimismo, el instrumento de recogida de información comprendía las siguientes variables demográficas: sexo, edad, estado civil, titulación académica, número de unidades del centro, zona en la que ejerce (según el número de habitantes de la localidad, provincia en la que se ubica el centro, nivel económico predominante de los alumnos, años de ejercicio docente, años de ejercicio en la función directiva como director, jefe de estudios o secretario, forma de acceso al cargo, horas dedicadas semanalmente a la docencia directa con los alumnos, promedio de horas dedicadas semanalmente al desarrollo de tareas directivas en el centro, nivel de preparación que considera poseer para desempeñar la función directiva, opinión sobre la forma actual de selección de director, opinión sobre el grado de autonomía que la administración 
Caballero Martínez, J., Fernández Camacho, C.R. y García Jiménez, E. (2003). Satisfacción de los secretarios de centros educativos. RELIEVE, v. 9, n. 2, p. 198-235.

http://www.uv.es/RELIEVE/v9n2/RELIEVEv9n2 7.htm

educativa permite al directivo, opinión sobre la duración en el cargo para que un equipo directivo pueda desarrollar plenamente su proyecto educativo, ¿ha recibido formación para ser director?, y cursos /seminarios o actividades de formación que ha realizado sobre temas de dirección.

\subsection{Muestra}

Se invitó a toda la población de centros no universitarios de Andalucía a responder el cuestionario, es decir, a los 2.681 Secretarios que ejercen el cargo en Andalucía, de los cuales han respondido 910 Secretarios que representan el 33,94\% de la población.

La muestra está compuesta por 910 Secretarios. Respecto a la variable PROVINCIA, en la Tabla 1 se recoge la distribución de frecuencias y porcentajes de éstos en cada una de las provincias andaluzas.

\begin{tabular}{|c|c|c|}
\hline PROVINCIA & FRECUENCIA & $\begin{array}{c}\text { PORCENTAJE EN FUNCIÓN } \\
\text { DE LA POBLACIÓN }\end{array}$ \\
\hline ALMERÍA & 83 & $3,10 \%$ \\
\hline GRANADA & 106 & $3,95 \%$ \\
\hline MÁLAGA & 143 & $5,33 \%$ \\
\hline JAÉN & 90 & $3,36 \%$ \\
\hline CÓRDOBA & 103 & $3,84 \%$ \\
\hline SEVILLA & 169 & $6,30 \%$ \\
\hline CÁDIZ & 157 & $5,86 \%$ \\
\hline HUELVA & 59 & $2,20 \%$ \\
\hline TOTAL & 910 & $33,94 \%$ \\
\hline
\end{tabular}

Tabla 1. Muestra de Secretarios para cada una de las provincias andaluzas

En la Tabla 1 se observa que la provincia con mayor porcentaje es la de Sevilla (el $6,30 \%$ ) y con menor, Huelva, cuyo porcentaje se aproxima al $2 \%$. La mayoría de los Secretarios que ejercen el cargo en los Centros Docentes Públicos de la Comunidad Autónoma de Andalucía son hombres, exactamente 658 (el 72,7\%), mientras que sólo 251 (el 27,3\%) son mujeres.

\subsection{Análisis de la información}

Para analizar las respuestas al cuestionario hemos seguido un doble procedimiento: de una parte, se han descrito las contestaciones de los Secretarios al instrumento; y, de otra, se han determinado las diferencias y simili- tudes de sus respuestas a partir de un conjunto de variables ilustrativas.

En el estudio descriptivo, utilizando la media se ha determinado la posición en torno a la que se sitúan la mayoría de las respuestas y utilizando la desviación típica hemos conocido la dispersión de las mismas. De igual modo, se ha realizado una distribución de frecuencias para todas las variables del cuestionario.

En el estudio de contraste, se han determinado las diferencias existentes aplicando pruebas no paramétricas (Kruskal-Wallis y Mann-Whitney) en el grado de satisfacción de los Secretarios en función de un conjunto de variables ilustrativas: provincia, sexo, 
edad, nivel de enseñanza, zona, años de docencia, forma de acceso a la dirección, horas de docencia, horas de coordinación, nivel de preparación estimado, perfil del Secretarios, autonomía, duración de su mandato y formación recibida. El criterio de elección de las pruebas de contraste hace referencia al nivel de medida de las variables implicadas en nuestro estudio, esto es, partiendo de la ordinalidad de las respuestas nos lleva a elegir pruebas no paramétricas.

\section{Resultados}

En este punto se va a profundizar sobre qué Secretarios están más satisfechos y cuáles menos en la Comunidad Autónoma Andaluza en función variables demográficas. Para ello, se han estudiado la posible existencia o ausencia de diferencias estadísticamente significativas en las opiniones a los distintos ítems en función de las anteriores variables. Presentaremos el ítem resumen de cada una de las dimensiones que conforman nuestro cuestionario y resumiremos brevemente los resultados obtenidos en los distintos ítems que forman parte de cada subescala del instrumento de medida.

\subsection{Satisfacción General}

El ítem 107 es el ítem resumen de todos los del Cuestionario. Su contenido hace referen- cia al nivel general de satisfacción. En este ítem, tan sólo 118 Secretarios (30\%) manifiestan un nivel de insatisfacción alta o moderada, mientras que 390 Secretarios $(42,9 \%)$ se muestran satisfechos o muy satisfechos a nivel personal y profesional. Además, cabe señalar que 302 Secretarios $(33,2 \%)$ no se muestran ni satisfechos ni insatisfechos con su situación personal o profesional. La media obtenida es de 3,35 puntos, lo que supone que los secretarios encuestados no muestran ni insatisfacción ni satisfacción. La desviación típica de 0,79 nos indica que existe poca dispersión en las opiniones.

En este ítem existen diferencias estadísticamente significativas en las variables siguientes: edad, zona en la que ejerce, años de docencia, años de secretario, horas dedicadas a la docencia, nivel de preparación, perfil del Secretarios y formación recibida. En la tabla siguiente, recogemos las distintas variables objeto de estudio, el valor del estadístico de contraste observado, los grados de libertad, el grado de significación y, finalmente, marcaremos con un asterisco $(*)$ en el caso de que las diferencias encontradas sean estadísticamente significativas, es decir, cuando el grado de significación sea menor que el nivel de error que estamos dispuesto a asumir $(\alpha=$ $0,05)$. 
Caballero Martínez, J., Fernández Camacho, C.R. y García Jiménez, E. (2003). Satisfacción de los secretarios de centros educativos. RELIEVE, v. 9, n. 2, p. 198-235.

http://www.uv.es/RELIEVE/v9n2/RELIEVEv9n2 7.htm

\begin{tabular}{|c|c|c|c|c|}
\hline VARIABLES & $\begin{array}{l}\text { Valor del estadístico de } \\
\text { contraste }\end{array}$ & $\mathrm{g} / \mathrm{l}$ & $\begin{array}{c}\text { GRADO DE } \\
\text { SIGNIFICACIÓN }\end{array}$ & $\begin{array}{c}\text { DIFERENCIAS } \\
\text { SIGNIFICATIVAS }\end{array}$ \\
\hline PROVINCIA & 34.069 & 28 & 0.199 & \\
\hline SEXO & 3.502 & 4 & 0.478 & \\
\hline EDAD & 15.629 & 8 & 0.048 & * \\
\hline E. INFANTIL & 13.102 & 8 & 0.108 & \\
\hline E. PRIMARIA & 16.091 & 8 & 0.187 & \\
\hline E. SECUNDARIA & 6.453 & 4 & 0.168 & \\
\hline F. PROFESIONAL & 11.648 & 4 & 0.168 & \\
\hline ZONA EN LA QUE EJERCE & 45.883 & 32 & 0.018 & * \\
\hline AÑOS DE DOCENCIA & 21.515 & 12 & 0.043 & * \\
\hline AÑOS DE SECRETARIO & 11.420 & 20 & 0.022 & $*$ \\
\hline FORMA DE ACCESO & 15.678 & 16 & 0.206 & \\
\hline HORAS DE DOCENCIA & 24.769 & 8 & 0.002 & $*$ \\
\hline HORAS INVESTIGACIÓN & 3.882 & 6 & 0.693 & \\
\hline NIVEL DE PREPARACIÓN & 22.266 & 8 & 0.004 & $*$ \\
\hline PERFIL DEL DIRECTOR & 59.761 & 20 & 0.000 & $*$ \\
\hline GRADO DE AUTONOMÍA & 13.412 & 12 & 0.340 & \\
\hline DURACIÓN EN EL CARGO & 33.180 & 32 & 0.409 & \\
\hline FORMACIÓN RECIBIDA & 51.480 & 20 & 0.007 & $*$ \\
\hline CURSOS REALIZADOS & 21.347 & 20 & 0.377 & \\
\hline INSTITUCIÓN ORGANIZADORA & 16.806 & 20 & 0.666 & \\
\hline
\end{tabular}

Tabla 2. Contraste de diferencias para el ítem final

Los resultados de este ítem resumen (Cuadro 2) nos permiten establecer las características diferenciales de los Secretarios de cen- tros educativos que se sienten más satisfechos y menos satisfechos en este ítem. 
Caballero Martínez, J., Fernández Camacho, C.R. y García Jiménez, E. (2003). Satisfacción de los secretarios de centros educativos. RELIEVE, v. 9, n. 2, p. 198-235.

http://www.uv.es/RELIEVE/v9n2/RELIEVEv9n2 7.htm

\begin{tabular}{|c|c|c|c|}
\hline \multicolumn{2}{|r|}{ Secretarios más satisfechos } & \multicolumn{2}{|r|}{ Secretarios menos satisfechos } \\
\hline a) & Tienen más edad (49.4\%) & a) & Son más jóvenes $(46.2 \%)$ \\
\hline b) & $\begin{array}{l}\text { Ejercen en pueblos de menos de } 5000 \\
\text { habitantes }(27.1 \%)\end{array}$ & b) & $\begin{array}{l}\text { Ejercen en pueblos de más de } 20000 \\
\text { habitantes }(23.7 \%) \text {. }\end{array}$ \\
\hline c) & Tienen más experiencia docente $(40 \%)$ & c) & Tienen menos experiencia docente $(27.1 \%)$ \\
\hline d) & $\begin{array}{l}\text { Dedican más de } 17 \text { horas semanales a la } \\
\text { atención a los alumnos }(61 \%)\end{array}$ & d) & $\begin{array}{l}\text { Dedican entre } 9 \text { y } 16 \text { horas semanales a la } \\
\text { atención de alumnos }(49.6 \%)\end{array}$ \\
\hline e) & $\begin{array}{l}\text { Consideran poseer un nivel alto para el } \\
\text { desempeño del cargo }(21 \%) \\
\text { Consideran que el perfil del Director }\end{array}$ & e) & $\begin{array}{l}\text { Consideran poseer un nivel bajo de } \\
\text { preparación para el desempeño del cargo } \\
(18.63 \%)\end{array}$ \\
\hline g) & $\begin{array}{l}\text { corresponde a aquellas personas con más } \\
\text { capacidad para realizar tareas de } \\
\text { dirección }(41.4 \%) \\
\text { Han realizado varias actividades de }\end{array}$ & f) & $\begin{array}{l}\text { Consideran que el perfil del Director } \\
\text { corresponde a aquellas personas con } \\
\text { motivaciones distintas de las pedagógicas } \\
(53.6 \%)\end{array}$ \\
\hline & formación $(50.5 \%)$ & g) & $\begin{array}{l}\text { No han realizado actividad alguna de } \\
\text { formación de directivos }(61.9 \%)\end{array}$ \\
\hline
\end{tabular}

Cuadro 2. Secretarios más satisfechos y menos satisfechos en el ítem resumen del Cuestionario

\section{Resultados de la subescala "Realización profesional"}

En la tabla siguiente, recogemos los resultados obtenidos para el ítem resumen de la dimensión Realización Profesional: En general, el nivel de logro alcanzado en mi trabajo como SECRETARIOS me produce un nivel de satisfacción.

La realización profesional es una de las formas en la que el hombre se realiza a sí mismo y alcanza la experiencia de su puesto de trabajo. Esta dimensión se describe en dieciocho ítems. En siete de ellos, la media está por debajo de tres, lo que indica que el valor predominante es la insatisfacción moderada, mientras que en el resto de ítems (once) la media es superior a tres puntos e inferior a cuatro puntos, lo que indica una ligera tendencia hacia la satisfacción moderada.

En el bloque de ítems en los que la media es inferior a tres puntos merece destacar los siguientes datos:

- "Las instituciones no facilitan ayuda para resolver los problemas" que se presentan a los Secretarios. En efecto, 518 Secretarios (58.9\%) se muestran insatisfechos o muy insatisfechos y sólo $11(1.3 \%)$ se muestran satisfechos o muy
$(1.3 \%)$ se muestran satisfechos o muy satisfechos.

- Los Secretarios disponen de muy pocas "posibilidades de promoción profesional /académica". 503 (56.6) se sitúan en niveles altos de insatisfacción y sólo 58 (7.5\%) se encuentran en niveles altos de satisfacción.

- "El complemento económico que reciben por desempeñar el cargo" es percibido como insatisfactorio o muy insatisfactorio por 496 Secretarios $(54.5 \%)$, mientras que para $127(14 \%)$ es satisfactorio o muy satisfactorio.

- "La tensión que comporta el trabajo del Secretario" es alta o muy alta para 352 Secretarios $(39.8 \%)$ y baja o muy baja para $145(16.4 \%)$.

-495 Secretarios (55.7\%) disponen de poco o muy poco "tiempo para realizar sus tareas", mientras que 183 (20.6\%) opinan lo contrario.

-362 Secretarios $(40.9 \%)$ piensan que "el desempeño del cargo les ofrece muy poca libertad y autonomía para tomar decisiones"; sin embargo, 169 (19.1\%) piensan de forma opuesta.

- "El reconocimiento social que percibe como secretario" es motivo de insatisfacción para $221(24.9 \%)$, mientras que es motivo de satisfacción para $154(17.4 \%)$. 
El segundo bloque de ítems, cuya media está comprendida entre 3.02 (ni satisfacción ni insatisfacción) y 3.74 (próximo al valor cuatro o satisfacción moderada), está formado por once ítems. Dentro de este bloque merecen destacarse los siguientes aspectos:

-103 (12.6\%) se encuentran insatisfechos con "el desempeño cotidiano del cargo", mientras que 500 (54.9) piensan lo contrario.

- Para 58 (6.3\%) "el carácter reversible del cargo (volver a ser docente)" es algo negativo, mientras que se encuentran de acuerdo con esta idea 463 (51.3\%) secretarios.

- "El clima del Centro, en relación con el desempeño de las funciones del Secretarios", es bueno o muy bueno para 469
Secretarios $(54.4 \%)$ y malo o muy malo para $87(11.1 \%)$.

-Para el 54.9\% de los Secretarios encuestados, "el nivel de logro alcanzado en su trabajo como Secretarios" ha sido bueno o muy bueno, mientras que para el $12.3 \%$ ha sido malo o muy malo.

En el Cuadro 3, se describen las características psicosociales de los Secretarios que están más satisfechos y menos satisfechos en esta dimensión. En este ítem existen diferencias estadísticamente significativas en las variables: nivel de preparación, perfil de secretarios, duración en el cargo, utilidad de estos cargos, edad, años de docencia, años como secretario, horas semanales dedicadas a la docencia y a la investigación.

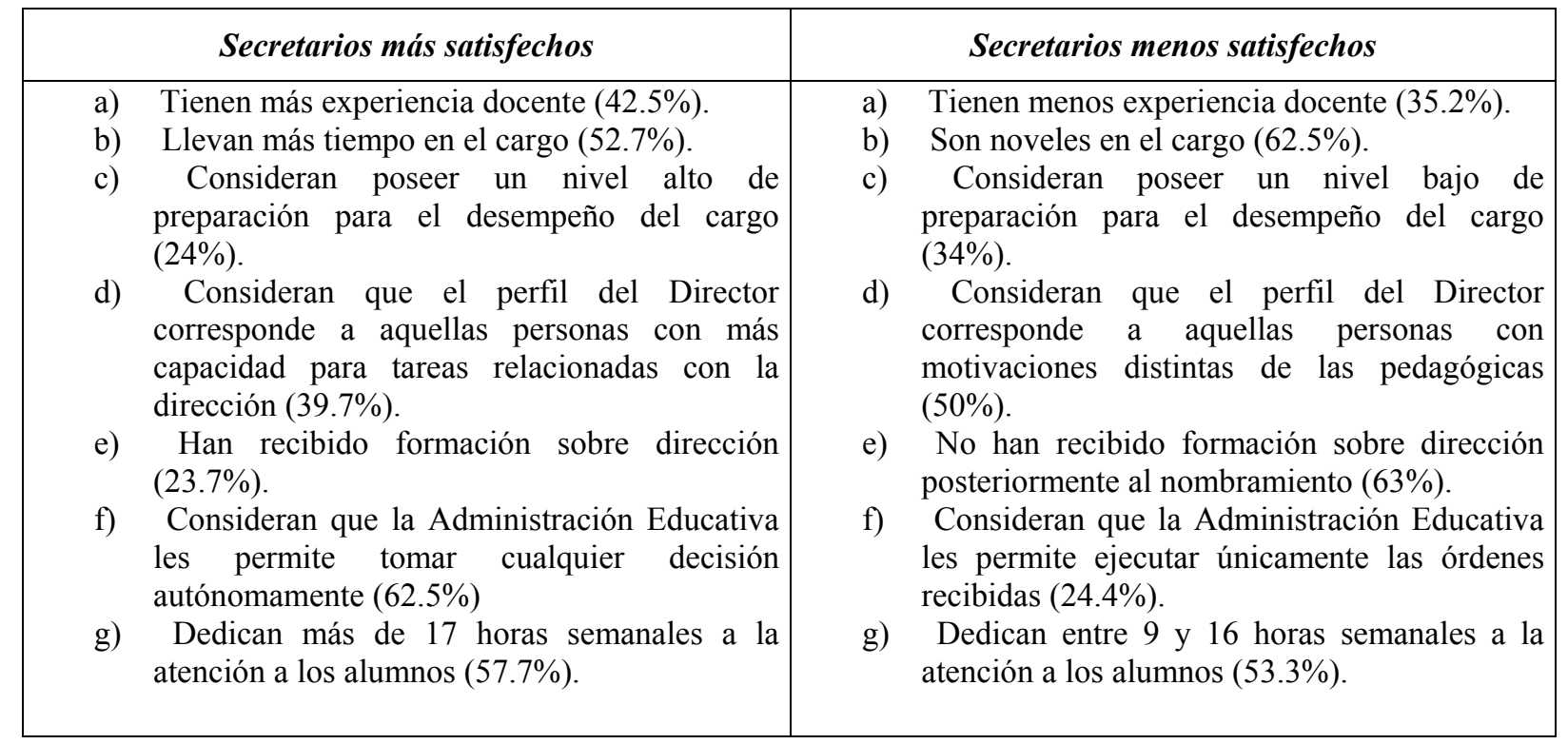

Cuadro 3. Secretarios más satisfechos y menos satisfechos en el ítem general de la dimensión“Realización profesional”

\subsection{La dimensión "Relaciones persona- les"}

En esta dimensión se han diferenciado varios ámbitos.

\subsection{1. Ámbito Interacción Director- Alumnos}

De los nueve ítems que comprende este ámbito, sólo dos tienen una media por debajo de tres puntos: el primero, el ítem 25, que hace referencia a "la dedicación e interés de los alumnos por el estudio" tiene una media de 2.35 puntos. 362 Secretarios $(41.4 \%)$ están moderadamente insatisfechos, 170 (19.4\%) muy insatisfechos, mientras que 113 $(12.9 \%)$ están moderadamente satisfechos y 
Caballero Martínez, J., Fernández Camacho, C.R. y García Jiménez, E. (2003). Satisfacción de los secretarios de centros educativos. RELIEVE, v. 9, n. 2, p. 198-235.

http://www.uv.es/RELIEVE/v9n2/RELIEVEv9n2 7.htm

sólo $12(1.4 \%)$ están muy satisfechos. El segundo, el ítem 26 , que hace referencia a "la participación de los alumnos en los órganos de gobierno" tiene una media de 2.95 puntos. 304 Secretarios (35.3\%) están insatisfechos, $280(32.4 \%)$ ni satisfechos ni insatisfechos y $279(32.3 \%)$ están satisfechos.

El resto de ítems (siete) alcanzan una media entre 3.14 y 3.91 puntos: El ítem 22 que hace referencia "al grado de cumplimiento de los derechos de los alumnos" muestra que 642 Secretarios $(73.6 \%)$ se encuentran en los niveles altos de satisfacción y 36 (4.4\%) en los niveles altos de insatisfacción. El ítem 19, que se refiere al "grado de aceptación que los Secretarios tienen entre los alumnos", muestra que hay 574 Secretarios (65.5) que se sienten satisfechos o muy satis- fechos y sólo 19 Secretarios (2.2\%) que se sienten insatisfechos o muy insatisfechos.

"En general, las relaciones académicas y personales con los alumnos" ha sido el ámbito más valorado positivamente por los Secretarios encuestados. Para 634 Secretarios $\quad(71.6 \%)$ las relaciones académicas y personales con los alumnos son buenas o muy buenas y malas o muy malas, para $55(6.2 \%)$. En este caso sólo existen diferencias estadísticamente significativas en las variables: zona en la que ejerce, utilidad de los cursos y perfil del Secretarios. En este ítem general, que engloba a los ocho anteriores, como puede verse en el Cuadro 4, muestra las características de los Secretarios más satisfechos y menos satisfechos en este ámbito.

\begin{tabular}{|c|c|}
\hline Secretarios más satisfechos & Secretarios menos satisfechos \\
\hline $\begin{array}{l}\text { a) Ejercen el cargo en la capital }(30.2 \%) \text {. } \\
\text { b) Ejercen en centros de Educación Secundaria } \\
\text { con menos unidades }(7.4 \%) \text {. } \\
\text { c) Consideran que el perfil del Director } \\
\text { corresponde a aquellas personas con capacidad } \\
\text { de realizar tareas propias de la dirección } \\
(31.4 \%)\end{array}$ & $\begin{array}{l}\text { a) Ejercen el cargo en localidades que cuentan } \\
\text { con entre } 5000 \text { y } 20000 \text { habitantes }(30.9 \%) \text {. } \\
\text { b) Ejercen en centros de Educación Secundaria } \\
\text { con más unidades }(7.2 \%) \\
\text { c) } \\
\text { consideran que el perfil del Director } \\
\text { motivaciones distintas a las pedagógicas } \\
(38.5 \%)\end{array}$ \\
\hline
\end{tabular}

Cuadro 4. Secretarios más satisfechos y menos satisfechos en el ítem general del ámbito "Interacción Directoralumnos"

\subsection{2. Ámbito "Relaciones con los Compañeros/as}

De los diez ítems que contiene este ámbito, todos han obtenido medias entre 3.49 (ítem 36) y 4.04 (ítem 28), excepto el ítem 32 , cuya media es sólo de 2.85 y el ítem 35 , cuya media es de 2.97.

El ítem 32, referido a "las posibilidades de intercambiar y compartir conocimientos con colegas de otros Centros"es el que registra un mayor porcentaje de Secretarios insatisfechos. En efecto, 328 Secretarios (36.1\%) se sienten insatisfechos o muy insatisfechos, 254 Secretarios $(27.9 \%)$ se sienten satisfe- chos o muy satisfechos y 304 (33.4\%) no se definen, es decir, no están ni satisfechos ni insatisfechos.

El ítem 35, referido a "la existencia de problemas, presiones "políticas" y resistencias entre los compañeros" registra también un porcentaje elevado de Secretarios insatisfechos. En este caso, 271 Secretarios $(29.8 \%)$ se sienten insatisfechos o muy insatisfechos, 344 Secretarios (37.8\%) no se definen y $233(28.5 \%)$ se sienten satisfechos o muy satisfechos.

Sin embargo, en el ítem 28, que determina "la integración con sus compañeros de Cen- 
Caballero Martínez, J., Fernández Camacho, C.R. y García Jiménez, E. (2003). Satisfacción de los secretarios de centros educativos. RELIEVE, v. 9, n. 2, p. 198-235.

http://www.uv.es/RELIEVE/v9n2/RELIEVEv9n2 7.htm

tro" se ha obtenido un mayor número de Secretarios satisfechos. Así, 249 Secretarios (27.4\%) se encuentran en los niveles altos de satisfacción, $3(0.3 \%)$ se encuentran en los niveles altos de insatisfacción y $143(15.7 \%)$ no se definen.

En síntesis, "el clima relacional que los Secretarios perciben entre los distintos niveles de convivencia profesional con sus compañeros" supone para 577 (63.5\%) un grado moderado o alto de satisfacción, para 74
(8.1\%) un grado moderado o alto de insatisfacción y para $238(26.2 \%)$ ni satisfacción ni insatisfacción.

En este ítem existen diferencias estadísticamente significativas en las variables sexo, zona en la que ejerce, horas de docencia y perfil. Este ítem general, que engloba a los nueve anteriores, como puede observarse en el Cuadro 5, muestra las características de los Secretarios más satisfechos y los menos satisfechos en este ámbito.

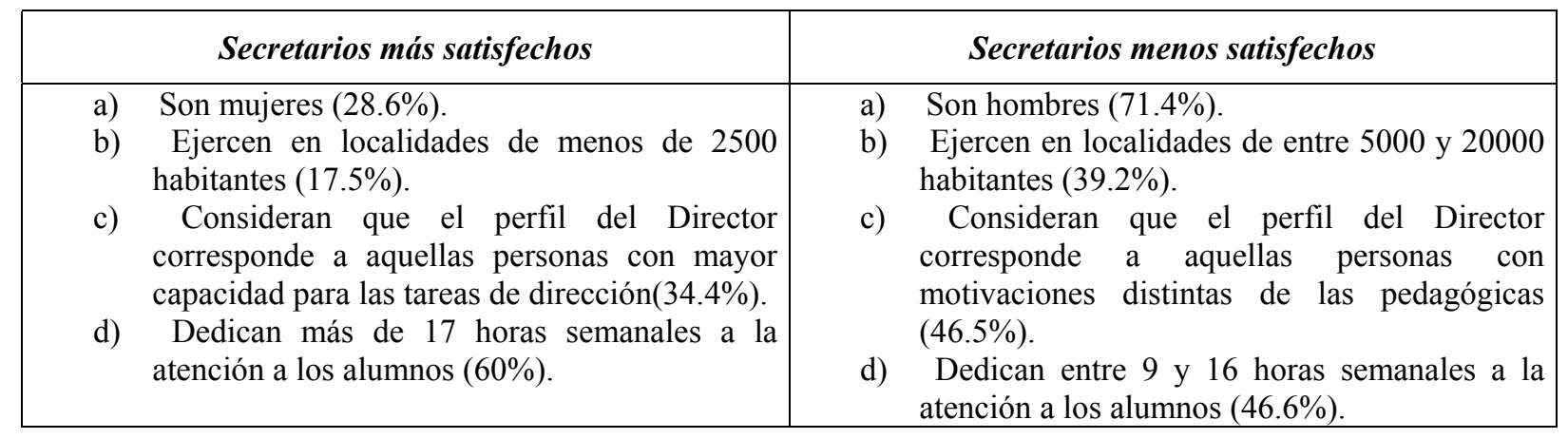

Cuadro 5. Secretarios más satisfechos y menos satisfechos en el ítem general del ámbito "Relaciones con los compañeros"

\subsection{3. "Ámbito Relaciones con los Pa- dres"}

En este ámbito la mayoría de los ítems (siete) ha obtenido una media inferior a tres puntos y los cuatro restantes han alcanzado una media de tres puntos.

Respecto a los ítems con una media inferior a tres puntos, merece destacarse el hecho de que existe "poca objetividad por parte de los padres al afrontar los problemas de sus hijos" (ítem 47), según la respuesta dada por la mayoría de los Secretarios. En efecto, $152(16.7 \%)$ se encuentran en los niveles altos de insatisfacción y sólo 14 $(1.5 \%)$ se encuentran en los niveles altos de satisfacción.

Un dato preocupante es la respuesta dada por la mayoría de los Secretarios al ítem 46, centrado en "la preocupación de los padres por el estudio de sus hijos”. Así, 481 Secretarios $(52.9 \%)$ se sienten insatisfechos o muy insatisfechos, $166(21.5 \%)$ satisfechos o muy satisfechos y 204 (22.4\%) ni satisfechos ni insatisfechos.

Otro hecho que merece especial atención es el que hace referencia a "la ayuda que prestan los padres al trabajo de los profesores" (ítem 43) y a "la participación de los padres en la resolución de problemas" (ítem 44). En el primer caso, 528 Secretarios (57\%) muestran niveles altos de insatisfacción, $164(18 \%)$ niveles altos de satisfacción y $292(32.1 \%)$ no se pronuncian. En el segundo caso, 388 Secretarios $(42.6 \%)$ se sienten insatisfechos o muy insatisfechos, 283 $(31.1 \%)$ no se pronuncian y $211(23.2 \%)$ se sienten satisfechos o muy satisfechos.

En resumen, "el clima relacional que los Secretarios perciben con los padres" les produce a 286 Secretarios $(31.5 \%)$ un grado de insatisfacción moderado o alto, a 262 (28.8\%) les produce un grado de satisfacción 
Caballero Martínez, J., Fernández Camacho, C.R. y García Jiménez, E. (2003). Satisfacción de los secretarios de centros educativos. RELIEVE, v. 9, n. 2, p. 198-235.

http://www.uv.es/RELIEVE/v9n2/RELIEVEv9n2 7.htm

moderado o alto y a $328(36 \%)$ no les produce ni satisfacción ni insatisfacción.

En este ítem existen diferencias significativas en las variables edad, zona en el que ejerce, decisión y nivel de preparación.
El ítem resumen que engloba a los nueve anteriores, como puede verse en el Cuadro 6 , muestra las características de los Secretarios más satisfechos y los menos satisfechos de este ámbito.

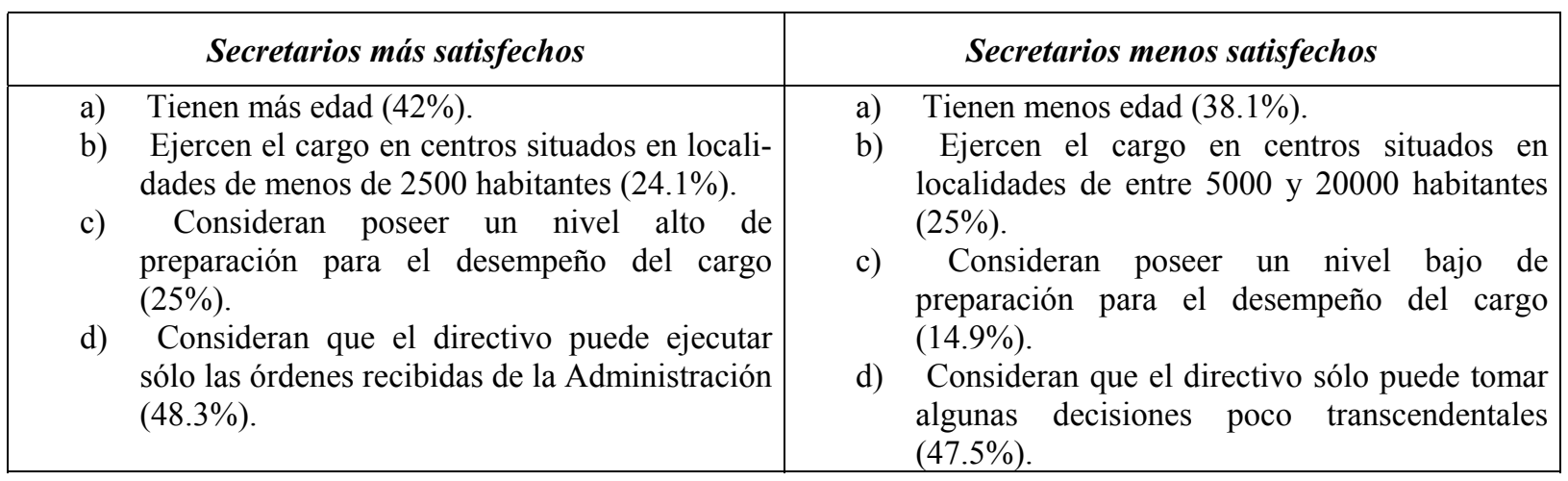

Cuadro 6. Secretarios más satisfechos y menos satisfechos en el ítem general del ámbito "Relaciones con los padres"

\subsection{4. Ámbito "Relaciones con la Administración Educativa y Municipal"}

"Las relaciones con la Administración Educativa y Municipal" ha sido el ámbito en el que se ha detectado un mayor grado de insatisfacción. En los diez ítem que comprende este ámbito, la media ha estado por debajo de tres puntos, exactamente entre 1.95 (ítem 52) y 2.76 puntos (ítem 49).

El ítem peor valorado por los Secretarios es el que hace referencia a "la atención de la Administración Educativa en las bajas del profesorado" (ítem 52). En efecto, de los 866 Secretarios que han respondido a este ítem, 650 Secretarios (71.4\%) se encuentran en los niveles altos de insatisfacción y sólo $111(10.2 \%)$ se sitúan en los niveles altos de satisfacción.

En el ítem 53, que alude a "la participación informativa en las decisiones que debe tomar la Administración”, existe prácticamente el mismo número de Secretarios insatisfechos que en el caso anterior: 609 (66.9\%); sin embargo, el número de Secretarios satisfechos es menor: $41(4.5 \%)$.
También cabe destacar que, según la opinión de la mayoría de los Secretarios, no existe "coordinación entre las Administraciones" (ítem 57). En este sentido, 559 Secretarios $(61.5 \%)$ se sienten insatisfechos o muy insatisfechos y sólo 30 Secretarios $(3.3 \%)$ se sienten satisfechos o muy satisfechos.

En general, "el clima que los Secretarios perciben de la Administración” les produce: a 536 Secretarios $(58.9 \%)$ un nivel moderado o alto de insatisfacción, a 78 (8.6\%) un nivel moderado o alto de satisfacción y a $258 \mathrm{Se}$ cretarios (el 28.4\%) ni satisfacción ni insatisfacción.

En este caso existen diferencias estadísticamente significativas en las variables provincia, edad, años de docencia, nivel de preparación, decisión y perfil.

El ítem general, como puede verse en la Cuadro 7, muestra las características de los Secretarios más insatisfechos y los menos insatisfechos en este ámbito. 
Caballero Martínez, J., Fernández Camacho, C.R. y García Jiménez, E. (2003). Satisfacción de los secretarios de centros educativos. RELIEVE, v. 9, n. 2, p. 198-235.

http://www.uv.es/RELIEVE/v9n2/RELIEVEv9n2 7.htm

\begin{tabular}{|c|c|c|}
\hline \multicolumn{2}{|r|}{ Secretarios menos insatisfechos } & Secretarios más insatisfechos \\
\hline a) & Ejercen el cargo en la provincia de Córdoba & a) Ejercen el cargo en la provincia de Cádiz \\
\hline b) & Tienen más edad $(16.8 \%)$ & Son más jóvenes $(4.4 \%)$. \\
\hline c) & Tienen menos experiencia docente $(70 \%)$ & Tienen más experiencia docente $(57 \%)$ \\
\hline d) & $\begin{array}{l}\text { Consideran poseer un nivel alto de } \\
\text { preparación }(6.7 \%) \text {. }\end{array}$ & $\begin{array}{l}\text { Consideran poseer un nivel bajo de } \\
\text { preparación }(2 \%) \text {. }\end{array}$ \\
\hline e) & $\begin{array}{l}\quad \text { Consideran que el perfil del Director } \\
\text { corresponde a aquellas personas con } \\
\text { motivaciones distintas de las pedagógicas } \\
(40.4 \%) \text {. }\end{array}$ & $\begin{array}{l}\text { Consideran que el perfil del Director } \\
\text { corresponde a aquellas personas con más } \\
\text { conocimientos sobre las tareas de dirección } \\
(38.2 \%) \text {. }\end{array}$ \\
\hline
\end{tabular}

Cuadro 7. Secretarios más insatisfechos y menos insatisfechos en el ítem general del ámbito "Relaciones con la Administración Educativa y Municipal”

\subsection{La dimensión "ESTRUCTURA ORGANIZATIVA"}

En esta dimensión se han diferenciado varios ámbitos.

\subsection{1. Ámbito "EI Centro Docente"}

El Centro Docente es el ámbito de mayor trascendencia, ya que en él adquieren sentido los procesos y los productos, las relaciones e interacciones, la dinámica de los diferentes roles, los estilos de dirección, convivencia, flujo de la información, participación, etc.

La evaluación del nivel de satisfacción de los Secretarios en sus respectivos Centros se centra en once ítems cuyos valores estadísticos son los siguientes.

El ítem 63, que hace referencia a "la disponibilidad de recursos materiales (espacio, mobiliario, aulas, etc.) en el Centro", está por debajo de la media teórica, alcanzando 2.74 puntos respectivamente. En este caso, hay 415 Secretarios $(45.6 \%)$ que se sienten insatisfechos o muy insatisfechos, 199 $(21.9 \%)$ que se sienten satisfechos o muy satisfechos y 274 (30.1\%) que no se pronuncian.

El ítem 67, referido al "nivel de diálogo y colaboración dentro del equipo directivo", tiene una media superior a cuatro puntos (4.26). Este ítem es el que ha obtenido la media más alta de los ciento siete ítems que comprende el cuestionario y, por tanto, es el ítem en el que existe un mayor número de Secretarios satisfechos, en concreto 737 (87.1\%). Sólo 35 (3.9\%) están insatisfechos.

Los ocho ítems restantes tienen medias comprendidas entre 3.91 puntos (ítem 68) y 3.00 puntos (ítem 64). El primero hace referencia "al clima de las reuniones". En él hay 639 Secretarios $(69.1 \%)$ que se sienten satisfechos o muy satisfechos, 59 (6.4\%) están insatisfechos o muy insatisfechos y 197 $(21.6 \%)$ no se pronuncian. En el segundo, que alude a "la disponibilidad de recursos tecnológicos", disminuye el porcentaje de Secretarios satisfechos (364, 40\%), aumenta el de insatisfechos $(331,36.4 \%)$ y 192 $(21.1 \%)$ no se pronuncian.

En síntesis, "la Estructura Organizativa que ofrecen los Centros" produce un grado moderado o alto de satisfacción a 587 Secretarios (65.5\%), un grado moderado o alto de insatisfacción a 59 Secretarios $(6.5 \%)$ e indiferencia a $237(26 \%)$.

Las variables en las que existen diferencias estadísticamente significativas son: años de Secretarios, horas de docencia y nivel de preparación.

El ítem general, como puede verse en el Cuadro 8, muestra las características de los Secretarios más satisfechos y los menos satisfechos en este ámbito. 
Caballero Martínez, J., Fernández Camacho, C.R. y García Jiménez, E. (2003). Satisfacción de los secretarios de centros educativos. RELIEVE, v. 9, n. 2, p. 198-235.

http://www.uv.es/RELIEVE/v9n2/RELIEVEv9n2 7.htm

\begin{tabular}{|c|c|}
\hline Secretarios más satisfechos & Secretarios menos satisfechos \\
\hline $\begin{array}{l}\text { a) Llevan más tiempo desempeñando el cargo } \\
(30.2 \%) \text {. } \\
\text { b) Consideran poseer un nivel alto de } \\
\text { preparación }(17.7 \%) \text {. } \\
\text { e) Dedican más tiempo a la docencia directa con } \\
\text { los alumnos }(20.1 \%) \text {. }\end{array}$ & $\begin{array}{l}\text { a) Son noveles en el cargo }(3.6 \%) \text {. } \\
\text { b) Consideran poseer un nivel bajo de } \\
\text { preparación }(11.9 \%) \text {. } \\
\text { c) Dedican menos tiempo a la docencia directa } \\
\text { con los alumnos }(3.9 \%) \text {. }\end{array}$ \\
\hline
\end{tabular}

Cuadro 8. Secretarios más satisfechos y menos satisfechos en el ítem general del ámbito“El Centro Docente”

\subsection{2. Ámbito "Los Equipos y Departa- mentos / Seminarios Docentes"}

Catorce ítems lo configuran. En este ámbito, junto con el referido a "Relaciones con la Administración Educativa y municipal", se produce un mayor grado de insatisfacción en los Secretarios encuestados. Así, el trabajo realizado por los equipos y /o seminarios, según las respuestas dadas por los Secretarios, es motivo de insatisfacción. De los catorce ítems que contiene este ámbito, sólo dos, "La configuración actual de los equipos docentes y/o seminarios" (ítem 70) y "el clima en que se desarrollan" (item 71) tienen una media superior a tres (3.22 puntos en el primer caso y 3.28 en el segundo). En el ítem setenta, 316 Secretarios $(34.7 \%)$ se muestran satisfechos o muy satisfechos y $166(18.2 \%)$ insatisfechos o muy insatisfechos. En el ítem setenta y uno, 377 Secretarios (41.5\%) se declaran satisfechos o muy satisfechos y 132 (14.5\%) insatisfechos o muy insatisfechos.

El ítem 78, referido al "reconocimiento $e$ incentivo, por parte de la Administración, al trabajo efectivamente realizado por parte de los coordinadores", es en el que se ha obtenido la media más baja del ámbito (2.04). En consecuencia, 593 Secretarios (65.1\%) se encuentran en los niveles altos de insatisfacción, mientras que sólo 59 Secretarios (6.4\%) se encuentran en los niveles altos de satisfacción.

El malestar de los Secretarios respecto a "la potenciación de la investigación en grupo" (ítem 77) se hace patente en los siguientes datos: 415 Secretarios $(45.6 \%)$ se sienten insa- tisfechos o muy insatisfechos, frente a 106 $(11.6 \%)$ que se sienten satisfechos o muy satisfechos.

Otros ítems que merecen destacarse, por el grado de insatisfacción que manifiestan los Secretarios respecto a su contenido y por la trascendencia de aquellos en el funcionamiento de los centros son: "La organización y disponibilidad de recursos económicos y materiales" (ítem 80). "La adecuación de la actividad individual del aula a una visión colectiva y consensuada de la escuela" (ítem 79). "La predisposición y creencia, por parte de los compañeros, en el trabajo de estos equipos y / o seminarios (ítem 75). "La dedicación de adaptaciones curriculares necesarias (niveles, ciclos, necesidades especiales, etc.) (ítem 74). "La dedicación a la coordinación curricular" (ítem 73). "La adecuación de la plantilla a las exigencias de la calidad de enseñanza" (ítem 82).

En síntesis, "el clima que los Secretarios perciben en los equipos y /o seminarios" supone para 240 Secretarios $(26.3 \%)$ un grado moderado o alto de insatisfacción, para 203 $(22.3 \%)$ un grado moderado o alto de satisfacción y para $395(43.4 \%)$ ni satisfacción ni insatisfacción.

Existen diferencias estadísticamente significativas en las variables nivel de formación y perfil.

El ítem general, como puede verse en el Cuadro 9, muestra las características de los Secretarios más insatisfechos y los menos insatisfechos en este ámbito. 
Caballero Martínez, J., Fernández Camacho, C.R. y García Jiménez, E. (2003). Satisfacción de los secretarios de centros educativos. RELIEVE, v. 9, n. 2, p. 198-235.

http://www.uv.es/RELIEVE/v9n2/RELIEVEv9n2 7.htm

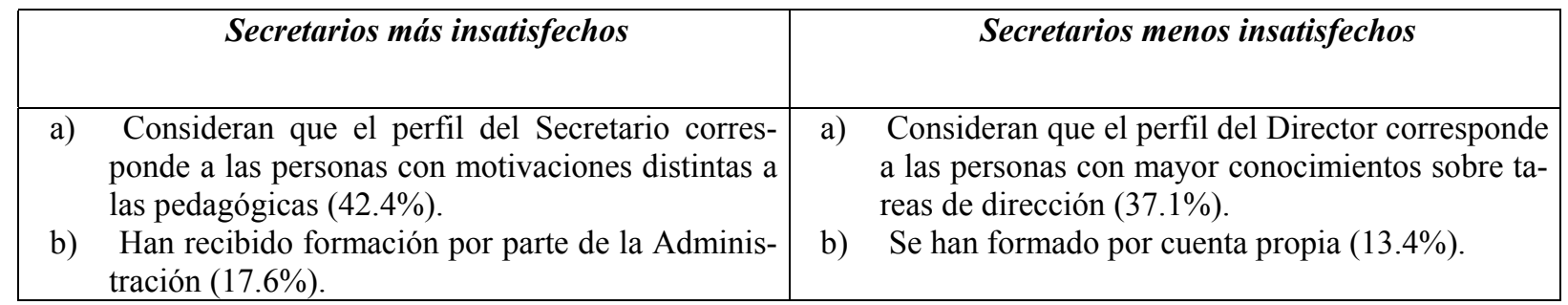

Cuadro 9. Secretarios más insatisfechos y menos insatisfechos en el ítem general del ámbito"Los Equipos y Departamentos / Seminarios Docentes

\subsection{3. Ámbito "El Claustro de Profesores"}

Éste ha sido el ámbito en que se ha producido un mayor grado de satisfacción de los Secretarios. De los once ítems que comprende, todos han obtenido una media superior a tres puntos, aunque ninguno ha llegado a cuatro puntos.

En el ítem 87 ("las competencias que la norma atribuye al Claustro") se registra un mayor número de Secretarios insatisfechos. Son 268 Secretarios (29.4\%) insatisfechos, frente a 337 (37.1\%) satisfechos.

El ítem en que se registra un mayor número de Secretarios satisfechos es el ochenta y cinco, que hace mención a "el clima existente entre los miembros del Claustro y el Secretario/a". Aquí son 656 Secretarios $(72.1 \%)$ los que se sienten satisfechos o muy satisfechos y 37 (4.1\%) los insatisfechos o muy insatisfechos.

En general, "el clima relacional que los Secretarios perciben en el Claustro de Profesores" produce a 526 Secretarios (57.8\%) un grado moderado o alto de satisfacción, a 79 $(8.7 \%)$ un grado moderado o alto de insatisfacción; aunque 269 Secretarios (29.6\%) no se pronuncian.

En este ítem existen diferencias estadísticamente significativas en las variables edad, Educación Primaria, zona, horas dedicadas a la docencia y perfil.

El ítem general, como puede verse en Cuadro 10, muestra las características de los Secretarios más satisfechos y los menos satisfechos en este ámbito.

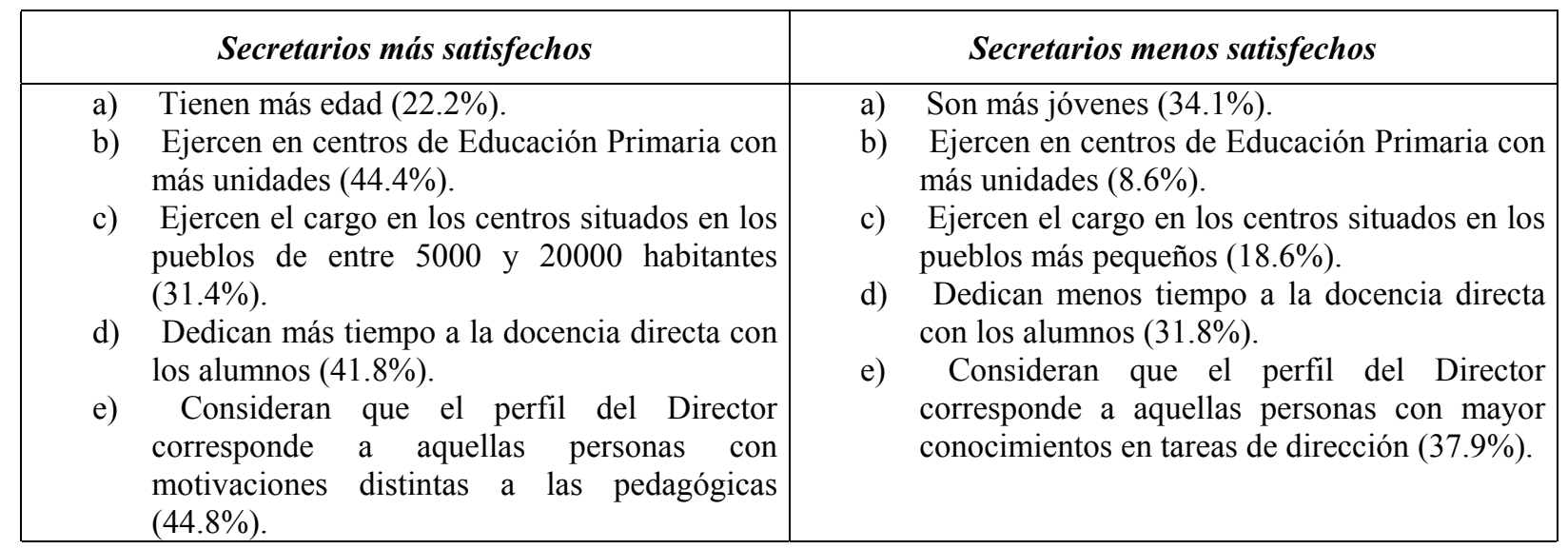

Cuadro 10. Secretarios más satisfechos y menos satisfechos en el ítem general del ámbito“ El Claustro de Profesores” 
Caballero Martínez, J., Fernández Camacho, C.R. y García Jiménez, E. (2003). Satisfacción de los secretarios de centros educativos. RELIEVE, v. 9, n. 2, p. 198-235.

http://www.uv.es/RELIEVE/v9n2/RELIEVEv9n2 7.htm

\subsection{4. Ámbito "El Consejo Escolar"}

El último ámbito de esta dimensión, comprende doce ítems y todos ellos, como en el ámbito referido al Claustro de Profesores, tienen una media superior a tres, por lo que las respuestas de los Secretarios son fundamentalmente satisfactorias.

El ítem 101, referido al "grado de cumplimiento de los acuerdos que se toman en las reuniones", ha obtenido un alto número de Secretarios satisfechos o muy satisfechos, en concreto, 630 Secretarios $(69.3 \%)$, mientras que los insatisfechos o muy insatisfechos sólo han sido $74(8.1 \%)$.

Los ítem en el que existe un mayor número de Secretarios insatisfechos es el 98, que hace referencia a "la clarificación y reflexión colectiva sobre las metas educativas del Centro" y el 105, que alude a "la influencia del secretario en la toma de decisiones en el Consejo Escolar. En estos aspectos, 225 Secretarios $(24.8 \%)$ y $271(18.8 \%)$, respectivamente, están insatisfechos o muy insatisfechos.

En síntesis, "el clima relacional que los Secretarios perciben en el Consejo Escolar" supone para 507 Secretarios (55.7\%) un nivel moderado o alto de satisfacción, para 101 (11.1\%) un nivel moderado o alto de insatisfacción y para $273(30 \%)$ ni satisfacción ni insatisfacción. En este ítem existen diferencias significativas en las variables nivel de preparación y horas dedicadas a la docencia.

El ítem resumen, como puede verse en el Cuadro 11, muestra las características de los Secretarios más satisfechos y menos satisfechos en este ámbito.

\begin{tabular}{|c|c|c|c|}
\hline \multicolumn{2}{|r|}{ Secretarios más satisfechos } & \multicolumn{2}{|r|}{ Secretarios menos satisfechos } \\
\hline & $\begin{array}{l}\text { Consideran poseer un nivel alto de } \\
\text { preparación para el desempeño del cargo } \\
(16.8 \%) \text {. }\end{array}$ & & $\begin{array}{l}\text { Consideran poseer un nivel bajo de } \\
\text { preparación para el desempeño del cargo } \\
(22.2 \%) \text {. }\end{array}$ \\
\hline b) & $\begin{array}{l}\text { Dedican más horas semanales a la docencia } \\
(27.5 \%) \text {. }\end{array}$ & b) & Dedican menos horas a la docencia $(46.8 \%)$ \\
\hline
\end{tabular}

Cuadro 11. Secretarios más satisfechos y menos satisfechos en el ítem genera del ámbito"El Consejo Escolar"

\section{Conclusiones Generales}

Las conclusiones obtenidas, tanto en el análisis descriptivo como en el análisis comparativo, hecho en función de las diversas variables demográficas, son las siguientes:

1. En la dimensión "Realización profesional", el grado máximo de insatisfacción de los secretarios se encuentra en estos aspectos: las facilidades institucionales para la resolución de problemas; las posibilidades de promoción profesional/académica; la tensión que comporta su trabajo; el complemento económico que perciben; el tiempo de que disponen para realizar sus tareas; la libertad y autonomía que les ofrece el cargo para tomar decisiones y las condiciones materiales y generales en las que realizan su trabajo. Por el contrario el mayor grado de satisfacción se encuentra en: el clima del centro, en relación con el desempeño de sus funciones; el carácter reversible del cargo; el nivel de logro alcanzado en su trabajo; el clima del centro y el desempeño cotidiano del cargo.

2. La segunda dimensión, "Relaciones personales", comprende cuatro ámbitos:

a) "Interacción Secretario-alumnos": De los nueve aspectos que comprende, sólo en dos (la dedicación e interés de los alumnos por el estudio y la participación de los alumnos en los órganos de gobierno) existe insatisfacción por parte de los Secretarios, mientras que, en el resto, el grado de satisfacción es moderado. 
b) "Relaciones con los compañeros": Los dos aspectos que les producen insatisfacción son: la existencia de problemas, presiones políticas y resistencias entre los compañeros y las posibilidades de intercambiar y compartir conocimientos con colegas de otros centros. Sin embargo, los ocho restantes les producen un grado de satisfacción moderada.

c) "Relaciones con los padres": En la mayoría de los aspectos (siete) existe un grado de insatisfacción moderada, destacando por ejemplo: la objetividad de los padres al afrontar los problemas de sus hijos, la preocupación de los padres por el estudio de sus hijos, la ayuda que prestan los padres al trabajo de los profesores, la participación de los padres en la resolución de problemas.

d) "Relaciones con la Administración educativa y Municipal": Es el ámbito que ha producido mayor grado de insatisfacción en los Secretarios, ya que, en los diez aspectos que comprende, el grado de insatisfacción ha sido alto o muy alto.

3. La tercera dimensión, "Estructura Organizativa", comprende cuatro ámbitos:

a) "El Centro Docente" les produce un grado de satisfacción moderada, excepto en algunos aspectos, como la disponibilidad de recursos materiales y recursos tecnológicos, que les produce insatisfacción moderada.

b) "Los Equipos y Departamentos" se encuentra en segundo lugar respecto al grado de insatisfacción, de los catorce aspectos que comprende, en doce de ellos existe un grado moderado o alto de insatisfacción, mientras que en los dos restantes no se pronuncian.

c) y d) "El Claustro de Profesores y el "Consejo Escolar": En estos dos ámbitos los Secretarios han manifestado en todos sus aspectos un grado de satisfacción moderada.

Por último, respecto al análisis comparativo hecho en función de las diversas variables demográficas, podemos concluir, en términos generales, que los Secretarios que se sienten más satisfechos son los que tienen más edad, más experiencia docente, llevan más tiempo ejerciendo el cargo, poseen un nivel alto de preparación, consideran poseer plena autonomía para tomar cualquier decisión y han realizado varias actividades de formación para directivos.

\section{Referencias Bibliográficas}

Álvarez, m.(1992). Elección y aceptación de los Directores: análisis de un estudio empírico. I Congreso Internacional sobre Dirección de Centros Docentes: La dirección factor clave de la calidad educativa. Bilbao: ICE-Universidad de Deusto.

Antúnez, S.(1993). Claves para la organización de centros escolares. Hacia una gestión participativa y autónoma. Barcelona: ICE/Horsori,

Caballero Martínez, J. (2001). Satisfacción e insatisfacción de los Directores Escolares. Granada: Grupo Editorial Universitario.

Cantón Mayo, I. (1996). La calidad total de los centros educativos. En Cantón, I. (coord..). Manual de Organización de centros educativos. Barcelona: Oikos-Tau.

Consejo Escolar de Estado (1994). Informe sobre el estado y situación del sistema educativo. Curso 19992-93. Madrid: MEC.

Federación de enseñanza de ccoo (1993). Encuesta al profesorado de primaria y secundaria de la enseñanza pública. Madrid: CIDE.

Fernández, j. (1991): Opinión de los profesores sobre su situación en la universidad. $G a$ ceta Complutense, 78, 25-32.

Gairín, j. (1995): Estudio de las necesidades de formación de los equipos directivos de los centros educativos. Madrid: Ministerio de educación y Ciencia - CIDE.

Gordillo, Mª V. (1988). La satisfacción profesional del profesorado: Consecuencias pa- 
ra la orientación educativa. En A. Villa. (Coord.): Perspectivas y problemas de la función docente. II Congreso Mundial Vasco. Madrid, Narcea. pp. 259-266.

Hanson, M. y Ulrich, c. (1992). El sistema español de dirección de centros docentes: un punto de vista crítico". I Congreso Internacional sobre Dirección de Centros Docentes: La dirección factor clave de la calidad educativa. Bilbao: ICE-Universidad de Deusto.

Herzberg, F., Mausner, B. y Snyderman, B. (1967). The motivation to work. ( $2^{\mathrm{a}}$ ed.). New York: Wiley.

Horovitz, J. y Jurgens Panak, M. (1994). La satisfacción total del cliente. Barcelona: Ed. Folio.

Immergart, GL. y Immegart, ML. (1995): Formación de directores de centros educativos. Bilbao: Universidad de Deusto.

Kreitner, R y Kinicki, A. (1997). Comportamiento de las organizaciones. Madrid: McGraw-Hill.

Loitegui Aldaz, J.R.(1990). Determinantes de la satisfacción laboral en empleados de la Administración Foral de Navarra. Tesis doctoral inédita, Facultad de Psicología, Universidad Complutense de Madrid.

Lorenzo, M. (1994). El liderazgo educativo en los Centros Docentes. Madrid: La Mura1la.

M.E.C.: Ley Orgánica 8/1985 de 3 de julio, reguladora del derecho a la Educación. (BOE 4-7-1985).

M.E.C.: Ley Orgánica 1/1990, de 3 de octubre, de Ordenación General del Sistema Educativo. (BOE 4-10-1990).

M.E.C.: Ley Orgánica 9/1995, de 20 de noviembre, de la Participación, la Evaluación y el Gobierno de los Centros Docentes. (BOE 21-11-1995).

M.E.C.: Ley Orgánica 10/2002, de 23 de diciembre, de Calidad de la Educación.

Muñoz Adanez, A.(1990). Satisfacción e insatisfacción en el trabajo. Tesis doctoral inédita, Facultad de Psicología, Universidad Complutense de Madrid.

Murillo, F.J. y Pérez-Albo, M.J. (1998). Implicaciones de la estabilidad de los directivos en la dinámica del centro docente. Bordón, 50(2), 145-158.

Padrón Hernández, M. (1994). Satisfacción profesional del profesorado. Tesis doctoral inédita, Facultad de Psicología, Universidad de La Laguna.

Porter, L.W. y Lawler, E.E. (1968). Managerial actitudes and perfomance. Homewood: IL, Irwin-Dorsey.

Robbins, S.P. (1987). Comportamiento organizacional. México: D.F. Prentice-Hall Hispanoamericana, S.A.

Robbins, S.P. y Coulter, M. (1996). Administración. México: Prentice-Hall Hispanoamericana, S.A.

Sáenz, O. y Lorenzo, M. (Eds.) (1993). La satisfacción del profesorado universitario. Granada: Servicio de Publicaciones de la Universidad de Granada

Sáenz, O. y Debón, S. (1995). Teorías sobre el deterioro de la dirección escolar. Rev. Interuniversitaria de Formación del Profesorado, 24, 193-206.

Sáenz, O. y Debón, S.(1997). El deterioro de la dirección escolar. Estudio de algunos factores. En M. Lorenzo, F. Salvador, f. y otros (Coords.): Organización y Dirección de Instituciones Educativas. Perspectivas actuales. Actas de las I Jornadas Andaluzas sobre Organización y Dirección de Centros Educativos. Granada: Grupo Editorial Universitario.

Vicente de, P. (coord.) (1995). Problemática de los profesores que ocupan cargos directivos y sus creencias acerca del ejercicio de la función directiva. Un estudio descriptivo. Enseñanza, 13, 127-152

Vicente de, P., Bolivar, A., Gutiérrez, D., Molina, E., Gallego, M. J., León, M. J., Fernández, M., Moral, C., Rodríguez, S. L. y Pérez, P. (1996). La problemática de la función directiva y la formación de los líde- 
Caballero Martínez, J., Fernández Camacho, C.R. y García Jiménez, E. (2003). Satisfacción de los secretarios de centros educativos. RELIEVE, v. 9, n. 2, p. 198-235.

http://www.uv.es/RELIEVE/v9n2/RELIEVEv9n2 7.htm

res escolares. Revista Investigación Educativa, 14 (1), 7-34

Vicente de, P. (coord.) (2001). Viaje al centro de la dirección de Instituciones Educativas. Bilbao: ICE - Universidad de Deusto

Villa, A., Villardón. L., Villar, L.M., De Vicente, P., Borrell, N. Laffitte, R. y Gairín, J. (1998). Principales dificultades de la Direc- ción de Centros Educativos en los primeros años de ejercicio. Bilbao: ICE-Universidad de Deusto

Weinert, B. (1985). Manual de Psicología de la Organización. Barcelona: Herder.

Zubieta, J.C. y Susinos, T. (1992). Las satisfacciones e insatisfacciones de los enseñantes. Madrid: CIDE.

CUESTIONARIO SOBRE EL NIVEL DE SATISFACCIÓN DE LOSIAS SECRETARIOSIAS DE LOS CENTROS DE EDUCACIÓN INFANTIL, PRIMARIA Y SECUNDARIA EN LA COMUNIDAD AUTÓNOMA ANDALUZA. \&

\section{DEPARTAMENTO DE DIDÁCTICA Y ORGANIZACIÓN ESCOLAR}

\section{DATOS GENERALES}

1. SEXO: Hombre $\square$ Mujer $\square$

2. EDAD: $\square$ años

\section{ESTADO CIVIL:}

Soltero/a $\square \quad$ Casado/a $\square \quad$ Separado/a $\square \quad$ Divorciado/a $\square$ Viudo/a $\square$

\section{TITULACIÓN ACADÉMICA:}

Maestro de Primera Enseñanza

Diplomado/a en

Licenciado/a en

Doctor/a en

Otras titulaciones

Si realiza actualmente otros estudios, diga cuáles: 
5. TIPO DE CENTRO DOCENTE AL QUE PERTENECE:

Público $\square \quad$ Privado $\square \quad$ Concertado $\square \quad$ Otro (especifique)

6. NIVELES:

Preescolar-Infantil $\quad \square \quad$ EGB-Primaria $\square \quad$ BUP- Secundaria $\square$

Formación Profesional

7. $N^{\circ}$ DE UNIDADES DEL CENTRO:

Preescolar-Infantil $\square$ EGB-Primaria

BUP-Secundaria $\quad \square \quad$ Formación Profesional $\square$

8. ZONA EN LA QUE EJERCE:

$\underline{\text { Pueblo }}$

$\underline{\text { Capital }}$

Menos de 2.500 habs.

Centro

De 2.500 a 5.000

Periferia

De 5.000 a 20.000

Zona deprimida

De 20.000 a 50.000

Más de 50.000

9. PROVINCIA DÓNDE SE UBICA EL CENTRO

10. NIVEL ECONÓMICO PREDOMINANTE DE LOS ALUMNOS/AS:

Bajo $\square \quad$ Medio-Bajo $\square \quad$ Medio $\square \quad$ Medio-Alto $\square \quad$ Alto $\square$

11. AÑOS DE EJERCICIO DOCENTE 


\section{AÑOS DE EJERCICIO EN LA FUNCIÓN DIRECTIVA COMO}

Director/a $\square \quad$ Jefe/a de estudios $\square \quad$ Secretario/a $\square \quad$ Otros (especificar).......

\section{FORMA DE ACCESO AL CARGO:}

a. Elección por el Consejo Escolar

b. Nombramiento directo de la Administración

c. Propuesto por el Titular de Centro

d. Nombrado por el Consejo Escolar a propuesta del Titular

Del centro

e. Otra (especificar)

14. ¿CUÁNTAS HORAS DEDICA SEMANALMENTE A LA DOCENCIA DIRECTA CON ALUMNOS/AS?

15. ¿QUÉ PROMEDIO DE HORAS DEDICA SEMANALMENTE AL DESARROLLO DE TAREAS DIRECTIVAS EN EL CENTRO?

Burocráticas $\square \quad$ Coordinación $\square \quad$ Investigación $\square \quad$ Orden $\square \quad$ Otras

16. ¿QUÉ NIVEL DE PREPARACIÓN CONSIDERA QUE POSEE PARA DESEMPEÑAR LA FUNCIÓN DE SECRETARIO/A?
Alto
Medio
Bajo

17. CONSIDERA QUE LA FORMA ACTUAL DE SELECCIÓN DE DIRECTOR/A POTENCIA LA ELECCIÓN DE AQUELLAS PERSONAS:

a. Con mayor capacidad de liderazgo en el Centro,

(con o sin conocimientos sobre las tareas de dirección)

b. Con más conocimientos sobre las tareas de dirección

c. Con más capacidad para las relaciones humanas

d. Con motivaciones distintas de las pedagógicas (de tipo ideológico, comodidad, amistad, etc. )

e. Con el deseo de evitar que accedan otras personas 
Caballero Martínez, J., Fernández Camacho, C.R. y García Jiménez, E. (2003). Satisfacción de los secretarios de centros educativos. RELIEVE, v. 9, n. 2, p. 198-235.

http://www.uv.es/RELIEVE/v9n2/RELIEVEv9n2 7.htm

\section{LA ADMINISTRACIÓN EDUCATIVA PERMITE AL DIRECTIVO}

a. Tomar cualquier decisión autónomamente

b. Tomar sólo algunas decisiones poco trascendentales

c. Ejecutar únicamente las órdenes recibidas de la Administración o del Titular del Centro

19. PARA QUE UN EQUIPO DIRECTIVO PUEDA DESARROLLAR PLENAMENTE SU PROYECTO EDUCATIVO, LA DURACIÓN EN EL CARGO DEBERÍA SER:

20. CALIFIQUE DE 1 (MÍNIMO) A 5 (MÁXIMO) SU NIVEL DE PREPARACIÓN EN CADA UNO DE LOS SIGUIENTES ÁMBITOS:

1. Planificación (Proyecto Educativo, Plan de Centro/Memoria, etc).

2. Evaluación de Centros

3. Evaluación de programas

4. Relaciones interpersonales

5. Legislación escolar en sus aspectos generales y específicos

6. Técnicas de gestión

7. Cumplimentar documentos oficiales

8. Organización general del Centro (Dptos., Equipos, Horarios)

9. Organización de los servicios escolares (comedor, transporte)

10. Organización de actividades complementarias

11. Infraestructura material y de espacios

12. Relaciones con los padres

13. Dinámica de grupos

14. Modelos, estrategias y técnicas relativas a la Formación del Profesorado en ejercicio

15. Psicología Aplicada y Orientación Escolar

16. Didáctica General: modelos didácticos, metodologías innovadoras, Sociología de la Educación, etc 
Caballero Martínez, J., Fernández Camacho, C.R. y García Jiménez, E. (2003). Satisfacción de los secretarios de centros educativos. RELIEVE, v. 9, n. 2, p. 198-235.

http://www.uv.es/RELIEVE/v9n2/RELIEVEv9n2 7.htm

\section{1. ¿HA RECIBIDO FORMACIÓN PARA SER SECRETARIO/A? Sí $\square$ No $\square$}

Por cuenta propia $\square$ Por la Administración $\square$ Anterior al nombramiento Posteriormente

\section{ESPECIFIQUE LOS CURSOS/SEMINARIOS O ACTIVIDADES DE FORMA- CIÓN QUE HA REALIZADO SOBRE TEMAS DE DIRECCIÓN}

Curso/Seminario/Actividad

Institución organizadora:

23. DE LAS MEDIDAS PRESENTADAS POR LA LOPEGCD PARA MEJORAR LA CALIDAD DE LA ENSEÑANZA QUE HACEN REFERENCIA A LA DIRECCIÓN DE LOS CENTROS PÚBLICOS, SEÑALE EL GRADO DE ACUERDO CON CADA UNA:

Para responder señale con una cruz de acuerdo con la siguiente clave:

$\mathrm{TA}=$ Totalmente de acuerdo

$\mathrm{A}=$ Más bien de acuerdo

$\mathrm{AD}=$ No puedo pronunciarme

$\mathrm{D}=$ Más bien en desacuerdo

$\mathrm{TD}=$ Totalmente en desacuerdo

\begin{tabular}{|c|c|c|c|c|c|}
\hline & TA & A & AD & $\mathrm{D}$ & TD \\
\hline $\begin{array}{l}\text { 1. El Consejo Escolar y Claustro colaborarán con la Inspección Educativa } \\
\text { en la evaluación del Centro }\end{array}$ & & & & & \\
\hline $\begin{array}{l}\text { 2. En ausencia de candidatos, o cuando éstos no hubiesen obtenido la } \\
\text { mayoría absoluta, la Administración Educativa podrá nombrar Director a } \\
\text { un profesor de otro Centro }\end{array}$ & & & & & \\
\hline $\begin{array}{l}\text { 3. Para acceder a la Dirección es requisito imprescindible haber sido acre- } \\
\text { ditado por la Administración Educativa. }\end{array}$ & & & & & \\
\hline 4. La duración del mandato del Director/a será de 4 años. & & & & & \\
\hline $\begin{array}{l}\text { 5. Los Directores/as participarán en el funcionamiento de las Direcciones } \\
\text { Provinciales. }\end{array}$ & & & & & \\
\hline
\end{tabular}


Caballero Martínez, J., Fernández Camacho, C.R. y García Jiménez, E. (2003). Satisfacción de los secretarios de centros educativos. RELIEVE, v. 9, n. 2, p. 198-235.

http://www.uv.es/RELIEVE/v9n2/RELIEVEv9n2 7.htm

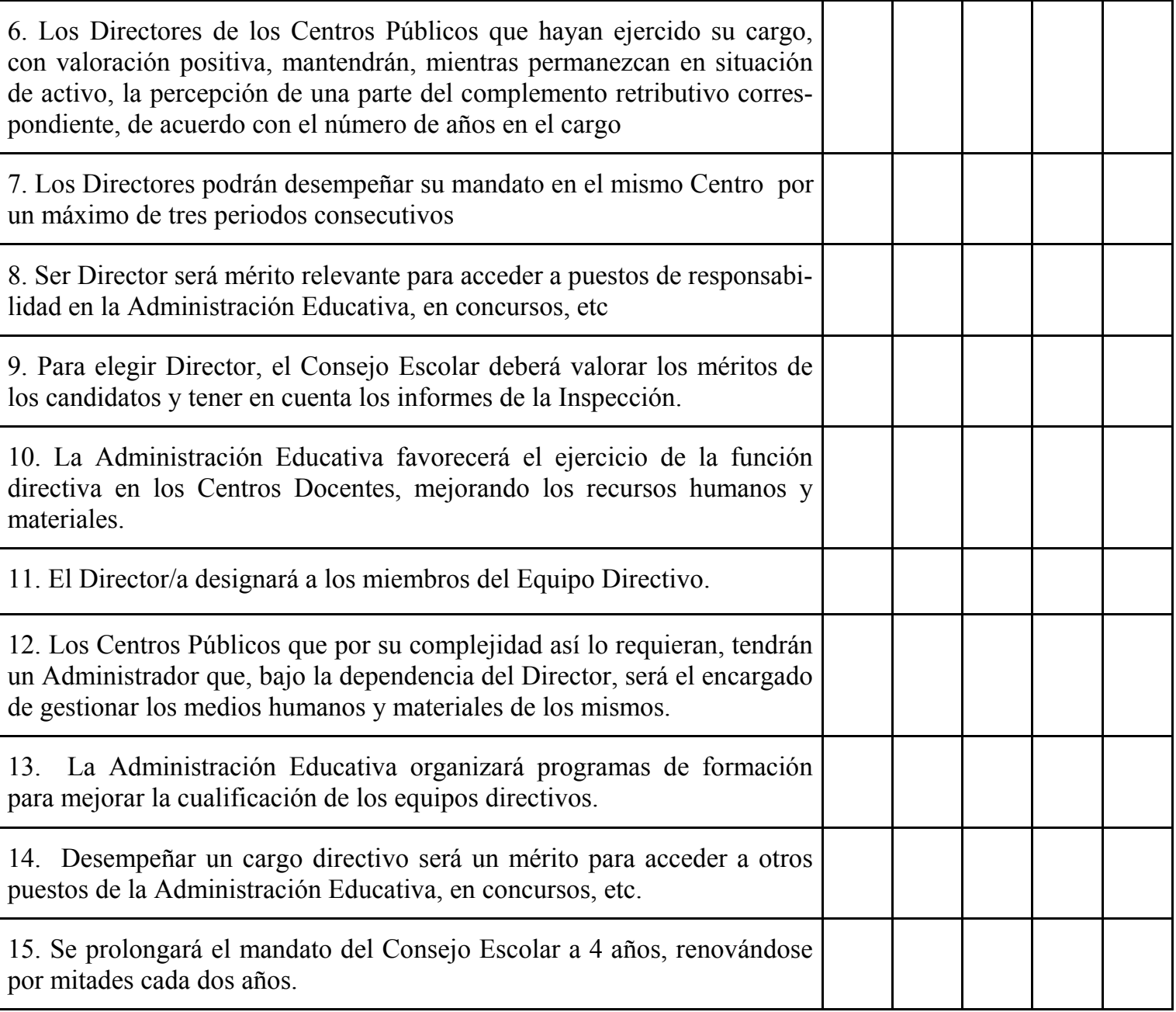

A continuación hallará varios bloques de proposiciones referidas a ámbitos diversos de la actuación del Secretario/a de Educación Infantil, Primaria, Secundaria, y Formación Profesional. Exprese, por favor, el nivel de satisfacción o insatisfacción que le producen las situaciones descritas.

Para responder, rodee con un círculo el número correspondiente de acuerdo con la siguiente clave:

$$
\begin{aligned}
& 1=\text { Insatisfacción alta } \\
& 2=\text { Insatisfacción moderada } \\
& 3=\text { Ni satisfacción ni insatisfacción } \\
& 4=\text { Satisfacción moderada } \\
& 5=\text { Satisfacción alta }
\end{aligned}
$$

\section{REALIZACIÓN PROFESIONAL}

\begin{tabular}{|l|c|c|c|c|c|}
\hline & Grado de satisfacción \\
\hline 1. El desempeño cotidiano del cargo. & 1 & 2 & 3 & 4 & 5 \\
\hline 2. El reconocimiento social que percibo como Secretario & 1 & 2 & 3 & 4 & 5 \\
\hline 3. Las condiciones generales en que realizo mi trabajo. & 1 & 2 & 3 & 4 & 5 \\
\hline
\end{tabular}


Caballero Martínez, J., Fernández Camacho, C.R. y García Jiménez, E. (2003). Satisfacción de los secretarios de centros educativos. RELIEVE, v. 9, n. 2, p. 198-235.

http://www.uv.es/RELIEVE/v9n2/RELIEVEv9n2 7.htm

\begin{tabular}{|c|c|c|c|c|c|}
\hline 4. La tensión que comporta mi trabajo. & 1 & 2 & 3 & 4 & 5 \\
\hline 5. El complemento económico que percibo como Secretario & 1 & 2 & 3 & 4 & 5 \\
\hline $\begin{array}{l}\text { 6. Las posibilidades de promoción profesional/académica que } \\
\text { dispongo. }\end{array}$ & 1 & 2 & 3 & 4 & 5 \\
\hline 7. La forma de acceder al cargo. & 1 & 2 & 3 & 4 & 5 \\
\hline 8. El carácter reversible del cargo (volver a ser docente) & 1 & 2 & 3 & 4 & 5 \\
\hline 9. Mi preparación profesional para desempeñar el cargo. & 1 & 2 & 3 & 4 & 5 \\
\hline 10. El tiempo que dispongo para realizar mis tareas. & 1 & 2 & 3 & 4 & 5 \\
\hline $\begin{array}{l}\text { 11. Las facilidades institucionales para la resolución de mis } \\
\text { problemas }\end{array}$ & 1 & 2 & 3 & 4 & 5 \\
\hline $\begin{array}{l}\text { 12.La libertad y autonomía que me ofrece el cargo de Secreta- } \\
\text { rio para tomar decisiones }\end{array}$ & 1 & 2 & 3 & 4 & 5 \\
\hline 13. El respaldo que tengo del profesorado del centro.. & 1 & 2 & 3 & 4 & 5 \\
\hline 14. Las condiciones materiales en que realizo mi trabajo & 1 & 2 & 3 & 4 & 5 \\
\hline $\begin{array}{l}\text { 15. El clima del centro en relación con el desempeño de mis } \\
\text { funciones }\end{array}$ & 1 & 2 & 3 & 4 & 5 \\
\hline $\begin{array}{l}\text { 16. Las oportunidades que tengo para ejecutar iniciativas y } \\
\text { desarrollar mis capacidades }\end{array}$ & 1 & 2 & 3 & 4 & 5 \\
\hline $\begin{array}{l}\text { 17. Las posibilidades que me ofrece el cargo de Secretario para } \\
\text { ser creativo y disfrutar de mi trabajo. }\end{array}$ & 1 & 2 & 3 & 4 & 5 \\
\hline $\begin{array}{l}\text { 18. En general, el nivel de logro alcanzado en mi trabajo como } \\
\text { Secretario me produce un nivel de satisfacción. }\end{array}$ & 1 & 2 & 3 & 4 & 5 \\
\hline
\end{tabular}

Exprese otros aspectos que le afecten en su realización profesional y valore el nivel de satisfacción

\section{RELACIONES PERSONALES}

\subsection{INTERACCIÓN SECRETARIO/A - ALUMNOS/AS}

\begin{tabular}{|l|l|l|l|l|l|}
\hline 19. El grado de aceptación que tengo entre los alumnos/as & 1 & 2 & 3 & 4 & 5 \\
\hline $\begin{array}{l}\text { 20. La flexibilidad y apertura que poseo ante las iniciativas y la } \\
\text { participación de los alumnos/as en el Centro. }\end{array}$ & 1 & 2 & 3 & 4 & 5 \\
\hline
\end{tabular}


Caballero Martínez, J., Fernández Camacho, C.R. y García Jiménez, E. (2003). Satisfacción de los secretarios de centros educativos. RELIEVE, v. 9, n. 2, p. 198-235.

http://www.uv.es/RELIEVE/v9n2/RELIEVEv9n2 7.htm

\begin{tabular}{|l|l|l|l|l|l|}
\hline 21. La existencia de un adecuado nivel de convivencia. & 1 & 2 & 3 & 4 & 5 \\
\hline $\begin{array}{l}\text { 22. El grado de cumplimiento de los derechos de los alum- } \\
\text { nos/as }\end{array}$ & 1 & 2 & 3 & 4 & 5 \\
\hline $\begin{array}{l}\text { 23. El respeto a las normas de convivencia dentro del Centro } \\
\text { por parte de los alumnos/as }\end{array}$ & 1 & 2 & 3 & 4 & 5 \\
\hline $\begin{array}{l}\text { 24. El nivel de participación y colaboración de los alumnos/as } \\
\text { en el Centro }\end{array}$ & 1 & 2 & 3 & 4 & 5 \\
\hline $\begin{array}{l}\text { 25. La dedicación e interés de los alumnos/as por el estudio } \\
\text { 26.La participación de los alumnos/as en los Órganos de Go- } \\
\text { bierno }\end{array}$ & 1 & 2 & 3 & 4 & 5 \\
\hline $\begin{array}{l}\text { 27.En general, mis relaciones académicas y personales con los } \\
\text { alumnos/as me produce un nivel de satisfacción }\end{array}$ & 1 & 2 & 3 & 4 & 5 \\
\hline
\end{tabular}

Exprese otros aspectos que le afecten en sus relaciones con el alumnado y valore el nivel de satisfacción

\subsection{RELACIONES CON LOS COMPAÑEROS/AS}

\begin{tabular}{|c|c|c|c|c|c|}
\hline 28. La integración con mis compañeros/as de $\mathrm{Ce}$ & 1 & 2 & 3 & 4 & 5 \\
\hline 29. La ayuda que recibo de mis colegas & 1 & 2 & 3 & 4 & 5 \\
\hline 30. El prestigio que poseo entre mis compañeros/as & 1 & 2 & 3 & 4 & 5 \\
\hline $\begin{array}{l}\text { 31. Las relaciones con mis compañeros/as fuera del horario } \\
\text { escolar. }\end{array}$ & 1 & 2 & 3 & 4 & 5 \\
\hline $\begin{array}{l}\text { 32. Las posibilidades de intercambiar y compartir conocimien- } \\
\text { tos colegas de otros Centros }\end{array}$ & 1 & 2 & 3 & 4 & 5 \\
\hline 33. El clima de trabajo que predomina entre los compañeros/as. & 1 & 2 & 3 & 4 & 5 \\
\hline $\begin{array}{l}\text { 34. El respeto a las aportaciones de cada profesor al desarrollo } \\
\text { de la escuela }\end{array}$ & 1 & 2 & 3 & 4 & 5 \\
\hline $\begin{array}{l}\text { 35. La existencia de problemas, presiones "políticas", resisten- } \\
\text { cias entre los compañeros/as }\end{array}$ & 1 & 2 & 3 & 4 & 5 \\
\hline $\begin{array}{l}\text { 36. El grado de cumplimiento y celo por el trabajo bien hecho } \\
\text { por parte de los compañeros/as }\end{array}$ & 1 & 2 & 3 & 4 & 5 \\
\hline 37. En gene & 1 & 2 & 3 & 4 & 5 \\
\hline
\end{tabular}


Caballero Martínez, J., Fernández Camacho, C.R. y García Jiménez, E. (2003). Satisfacción de los secretarios de centros educativos. RELIEVE, v. 9, n. 2, p. 198-235.

http://www.uv.es/RELIEVE/v9n2/RELIEVEv9n2 7.htm

tos niveles de convivencia profesional con mis compañeros/as me produce un nivel de satisfacción

Exprese otros aspectos que le afecten en sus relaciones con los/as compañeros/as y valore el nivel de satisfacción

\subsection{RELACIÓN CON LOS PADRES}

\begin{tabular}{|c|c|c|c|c|c|}
\hline 38. La ayuda y apoyo que recibo de parte de los padres & 1 & 2 & 3 & 4 & 5 \\
\hline 39. El reconocimiento de mi trabajo por los padres & 1 & 2 & 3 & 4 & 5 \\
\hline $\begin{array}{l}\text { 40. Las exigencias de los padres respecto de la Dirección del } \\
\text { Centro }\end{array}$ & 1 & 2 & 3 & 4 & 5 \\
\hline $\begin{array}{l}\text { 41. El respeto de los padres hacia las competencias de los pro- } \\
\text { fesores y la Dirección }\end{array}$ & 1 & 2 & 3 & 4 & 5 \\
\hline 42. Las relaciones entre padres y profesores & 1 & 2 & 3 & 4 & 5 \\
\hline 43. La ayuda que prestan al trabajo de los profesores & 1 & 2 & 3 & 4 & 5 \\
\hline $\begin{array}{l}\text { 44. La participación de los padres en la resolución de proble- } \\
\text { mas }\end{array}$ & 1 & 2 & 3 & 4 & 5 \\
\hline 45. La participación de los padres en los Órganos de Gobierno. & 1 & 2 & 3 & 4 & 5 \\
\hline 46. La preocupación de los padres por el estudio de sus hijos. & 1 & 2 & 3 & 4 & 5 \\
\hline $\begin{array}{l}\text { 47. La objetividad de los padres al afrontar los problemas de } \\
\text { sus hijos }\end{array}$ & 1 & 2 & 3 & 4 & 5 \\
\hline $\begin{array}{l}\text { 48. En general, el clima relacional que percibo con los padres } \\
\text { me produce un nivel de satisfacción }\end{array}$ & 1 & 2 & 3 & 4 & 5 \\
\hline
\end{tabular}

Exprese otros aspectos que le afecten en su relación con los padres y valore el nivel de satisfacción

\subsection{RELACIONES CON LA ADMINISTRACIÓN EDUCATIVA Y MUNICIPAL}

\begin{tabular}{|l|l|l|l|l|l|}
\hline 49. La ayuda e información que recibo del Inspector & 1 & 2 & 3 & 4 & 5 \\
\hline $\begin{array}{l}\text { 50. Los medios y recursos que la Administración pone a mi dispo- } \\
\text { sición }\end{array}$ & 1 & 2 & 3 & 4 & 5 \\
\hline
\end{tabular}


Caballero Martínez, J., Fernández Camacho, C.R. y García Jiménez, E. (2003). Satisfacción de los secretarios de centros educativos. RELIEVE, v. 9, n. 2, p. 198-235.

http://www.uv.es/RELIEVE/v9n2/RELIEVEv9n2 7.htm

\begin{tabular}{|l|l|l|l|l|l|}
\hline 51. El apoyo de la Administración a la labor de la Dirección. & 1 & 2 & 3 & 4 & 5 \\
\hline $\begin{array}{l}\text { 52. La atención de la Administración educativa en las bajas del } \\
\text { profesorado }\end{array}$ & 1 & 2 & 3 & 4 & 5 \\
\hline $\begin{array}{l}\text { 53. La participación informativa en las decisiones que debe tomar } \\
\text { la Administración }\end{array}$ & 1 & 2 & 3 & 4 & 5 \\
\hline $\begin{array}{l}\text { 54. La información o ayuda que recibo de los equipos de Apoyo } \\
\text { Externo }\end{array}$ & 1 & 2 & 3 & 4 & 5 \\
\hline $\begin{array}{l}\text { 55. La cooperación del Ayuntamiento con el Centro } \\
\text { Culturales, Deportivas, etc }\end{array}$ & 1 & 2 & 3 & 4 & 5 \\
\hline $\begin{array}{l}\text { 56. La colaboración de Asociaciones de Vecinos, Asociaciones } \\
\text { 57. La coordinación entre Administraciones }\end{array}$ & 1 & 2 & 3 & 4 & 5 \\
\hline $\begin{array}{l}\text { 58. En general, el clima que percibo de la Administración me } \\
\text { produce un nivel de satisfacción }\end{array}$ & 1 & 2 & 3 & 4 & 5 \\
\hline
\end{tabular}

Exprese otros aspectos que le afecten en sus relaciones con la Administración Educativa y Municipal y valore el nivel de satisfacción

3. ESTRUCTURA ORGANIZATIVA ( Organización y funcionamiento del Centro).

\subsection{EL CENTRO DOCENTE}

\begin{tabular}{|l|l|l|l|l|l|}
\hline 59. La existencia de un proyecto de trabajo común y participativo & 1 & 2 & 3 & 4 & 5 \\
\hline 60. La existencia de objetivos de Centro claramente definidos & 1 & 2 & 3 & 4 & 5 \\
\hline 61. La organización académica de mi Centro & 1 & 2 & 3 & 4 & 5 \\
\hline 62. La planificación adecuada de las tareas & 1 & 2 & 3 & 4 & 5 \\
\hline $\begin{array}{l}\text { 63. La disponibilidad de recurso materiales (espacios, mobiliario, } \\
\text { aulas, etc.) en mi Centro }\end{array}$ & 1 & 2 & 3 & 4 & 5 \\
\hline $\begin{array}{l}\text { 64. La disponibilidad de recursos tecnológicos (video, ordenadores, } \\
\text { etc.) en mi Centro }\end{array}$ & 1 & 2 & 3 & 4 & 5 \\
\hline $\begin{array}{l}\text { 65. las posibilidades de participación en la vida del Centro } \\
\text { 66. La coordinación de todo el profesorado en aspectos fundamen- } \\
\text { tales }\end{array}$ & 1 & 2 & 3 & 4 & 5 \\
\hline 67. El nivel de diálogo y colaboración dentro del equipo directivo & 1 & 2 & 3 & 4 & 5 \\
\hline
\end{tabular}


Caballero Martínez, J., Fernández Camacho, C.R. y García Jiménez, E. (2003). Satisfacción de los secretarios de centros educativos. RELIEVE, v. 9, n. 2, p. 198-235.

http://www.uv.es/RELIEVE/v9n2/RELIEVEv9n2 7.htm

68. El clima de las reuniones

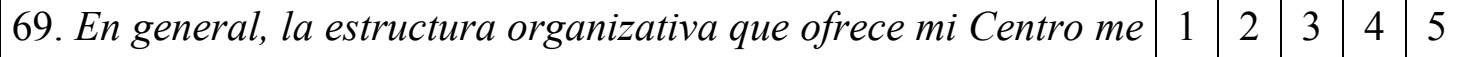
produce un nivel de satisfacción

Exprese otros aspectos que le afecten en relación con el Centro Docente y valore el nivel de satisfacción

\subsection{LOS EQUIPOS Y DEPARTAMENTOS / SEMINARIOS DOCENTES}

\begin{tabular}{|l|l|l|l|l|l|}
\hline 70. La configuración actual de los equipos docentes y/o seminarios & 1 & 2 & 3 & 4 & 5 \\
\hline 71. El clima en que se desarrollan los equipos y/o seminarios & 1 & 2 & 3 & 4 & 5 \\
\hline $\begin{array}{l}\text { 72. La preocupación de los equipos y/o seminarios por implantar } \\
\text { nuevas metodologías, sugerir actividades, motivar el trabajo, asistir } \\
\text { a los profesores en su docencia, etc. }\end{array}$ & 1 & 2 & 3 & 4 & 5 \\
\hline $\begin{array}{l}\text { 73. La dedicación a la coordinación curricular } \\
\text { 74. La dedicación de adaptaciones curriculares necesarias (niveles, } \\
\text { ciclos, necesidades especiales, etc.) }\end{array}$ & 1 & 2 & 3 & 4 & 5 \\
\hline $\begin{array}{l}\text { 75. La predisposición y creencia, por parte de los compañeros, en el } \\
\text { trabajo de estos equipos y/o seminarios }\end{array}$ & 1 & 2 & 3 & 4 & 5 \\
\hline $\begin{array}{l}\text { 76. La coordinación existente respecto a programas, metodología, } \\
\text { evaluación }\end{array}$ & 1 & 2 & 3 & 4 & 5 \\
\hline $\begin{array}{l}\text { 77. La potenciación de la investigación en grupo } \\
\text { 78. El reconocimiento e incentivo, por parte de la Administración } \\
\text { al trabajo efectivamente realizado por parte de los coordinadores }\end{array}$ & 1 & 2 & 3 & 4 & 5 \\
\hline $\begin{array}{l}\text { 79. La adecuación de la actividad individual del aula a una visión } \\
\text { colectiva y consensuada de la escuela }\end{array}$ & 1 & 2 & 3 & 4 & 5 \\
\hline $\begin{array}{l}\text { 80. La organización y disponibilidad de recursos económicos y } \\
\text { materiales }\end{array}$ & 1 & 2 & 3 & 4 & 5 \\
\hline $\begin{array}{l}\text { 81. La operatividad y eficacia de las reuniones } \\
\text { 82. La adecuación de la plantilla a las exigencias de calidad de en- } \\
\text { senanza }\end{array}$ & 1 & 2 & 3 & 4 & 5 \\
\hline $\begin{array}{l}\text { 83. En general, el clima que percibo en los equipos y/o seminarios } \\
\text { (1) }\end{array}$ & 1 & 2 & 3 & 4 & 5 \\
\hline
\end{tabular}


Caballero Martínez, J., Fernández Camacho, C.R. y García Jiménez, E. (2003). Satisfacción de los secretarios de centros educativos. RELIEVE, v. 9, n. 2, p. 198-235.

http://www.uv.es/RELIEVE/v9n2/RELIEVEv9n2 7.htm

me produce un nivel de satisfacción

Exprese otros aspectos que le afecten en relación con los equipos y/o seminarios y valore el nivel de satisfacción

\subsection{EL CLAUSTRO DE PROFESORES}

\begin{tabular}{|l|l|l|l|l|l|}
\hline $\begin{array}{l}\text { 84. La eficacia del Claustro como órgano para la discusión y } \\
\text { toma de decisiones sobre cuestiones profesionales del trabajo } \\
\text { docente }\end{array}$ & 2 & 3 & 4 & 5 \\
\hline $\begin{array}{l}\text { 85. El clima existente entre los miembros del Claustro y el } \\
\text { Director }\end{array}$ & 1 & 2 & 3 & 4 & 5 \\
\hline $\begin{array}{l}\text { 86. La influencia del Claustro en las decisiones que se toman } \\
\text { en el Centro }\end{array}$ & 1 & 2 & 3 & 4 & 5 \\
\hline 87. Las competencias que la norma atribuye al Claustro & 1 & 2 & 3 & 4 & 5 \\
\hline $\begin{array}{l}\text { 88. La participación del profesorado } \\
\text { 89. La colaboración y participación de los profesores en la } \\
\text { elaboración del P.C.: F.E., P.C.C., R.O.F }\end{array}$ & 1 & 2 & 3 & 4 & 5 \\
\hline 90. La planificación de las reuniones del Claustro & 1 & 2 & 3 & 4 & 5 \\
\hline 91. La eficacia y la operatividad de las reuniones & 1 & 2 & 3 & 4 & 5 \\
\hline $\begin{array}{l}\text { 92. El grado de cumplimiento de los acuerdos que se toman en } \\
\text { las reuniones }\end{array}$ & 1 & 2 & 3 & 4 & 5 \\
\hline $\begin{array}{l}\text { 93. La relación de equilibrio y estabilidad entre el Consejo } \\
\text { Escolar y el Claustro de profesores }\end{array}$ & 1 & 2 & 3 & 4 & 5 \\
\hline $\begin{array}{l}\text { 94. En general, el clima relacional que percibo en el Claustro } \\
\text { de Profesores me produce un nivel de satisfacción }\end{array}$ & 1 & 2 & 3 & 4 & 5 \\
\hline
\end{tabular}

Exprese otros aspectos que le afecten en relación con el Claustro y valore el nivel de satisfacción

\subsection{EL CONSEJO ESCOLAR}

\begin{tabular}{|l|l|l|l|l|l|} 
95. La eficacia del Consejo Escolar como órgano máximo de & 1 & 2 & 3 & 4 & 5
\end{tabular} 
Caballero Martínez, J., Fernández Camacho, C.R. y García Jiménez, E. (2003). Satisfacción de los secretarios de centros educativos. RELIEVE, v. 9, n. 2, p. 198-235.

http://www.uv.es/RELIEVE/v9n2/RELIEVEv9n2 7.htm

\begin{tabular}{|l|l|l|l|l|l|}
\hline gestión y participación de la Comunidad Educativa & & & & \\
\hline 96. La eficacia en el cumplimiento de las funciones propia & 1 & 2 & 3 & 4 & 5 \\
\hline 97. El consenso y compromiso sobre el tipo de educación & 1 & 2 & 3 & 4 & 5 \\
\hline $\begin{array}{l}\text { 98. La clarificación y reflexión colectiva sobre las metas edu- } \\
\text { cativas del Centro }\end{array}$ & 1 & 2 & 3 & 4 & 5 \\
\hline $\begin{array}{l}\text { 99. La existencia de un Plan de Centro que sea algo más que } \\
\text { una exigencia formal }\end{array}$ & 1 & 2 & 3 & 4 & 5 \\
\hline \begin{tabular}{l} 
100. La operatividad y dinámica de las reuniones \\
\hline $\begin{array}{l}\text { 101. El grado de cumplimiento de los acuerdos que se toma } \\
\text { en las reuniones }\end{array}$
\end{tabular} & 1 & 2 & 3 & 4 & 5 \\
\hline $\begin{array}{l}\text { 102. Las relaciones entre padres, profesores y alumnos } \\
\text { 103. El grado de aceptación, coordinación e integración de los } \\
\text { diferentes sectores que forman parte del Consejo Escolar }\end{array}$ & 1 & 2 & 3 & 4 & 5 \\
\hline $\begin{array}{l}\text { 104. El ambiente de colaboración, coordinación y respeto } \\
\text { entre sus miembros }\end{array}$ & 1 & 2 & 3 & 4 & 5 \\
\hline $\begin{array}{l}\text { 105. La influencia del Director/a en la toma de decisiones en } \\
\text { el Consejo Escolar }\end{array}$ & 1 & 2 & 3 & 4 & 5 \\
\hline $\begin{array}{l}\text { 106. En general, el clima que percibo en el Consejo Escolar } \\
\text { me produce un nivel de satisfacción }\end{array}$ & 1 & 2 & 3 & 4 & 5 \\
\hline
\end{tabular}

Exprese otros aspectos que le afecten en relación con el Consejo Escolar y valore el nivel de satisfacción

Otras causas de satisfacción/insatisfacción

107. EN RESUMEN, MI NIVEL DE SATISFACCIÓN ES DE

\begin{tabular}{l|l|l|l|l|}
1 & 2 & 3 & 4 & 5 \\
\hline
\end{tabular} 


\section{ABOUT THE AUTHORS / SOBRE LOS AUTORES}

Juan Caballero Martínez (jcaballe@ugr.es). Es Profesor doctor Asociado del Departamento de Didáctica y Organización Escolar de la Universidad de Granada, y miembro, desde su fundación, del grupo de investigación EDINVEST, cuya línea de investigación de mayor importancia es el énfasis en el análisis de la realidad educativa andaluza estudiada desde foros, jornadas y simposium así como en investigaciones que justifican, constatan y reafirman planteamientos teóricos esgrimidos desde diferentes y autores. Dirección de contacto: Departamento de Didáctica y Organización Escolar. Facultad de Ciencias de la Educación. Campus La Cartuja, s/n. 18071 Granada.

Carmen R. Fernández Camacho (crfernandez@us.es). Es Profesora-Tutora de la U.N.E.D. en el centro Asociado de Huelva, colaborando en tareas docentes en disciplinas relacionadas con la investigación educativa. También es miembro del grupo de investigación SUROESTE, de la Universidad de Huelva. Asimismo, su principal línea de investigación se encuentra focalizada hacia la medición educativa, más concretamente, hacia validación de instrumentos de medida. Dirección de contacto: Dpto. Departamento de Didáctica y Organización Escolar y Métodos de Investigación y Diagnóstico en Educación. Facultad de Ciencias de la Educación. C/ Camilo José Cela, s/n. 41018 Sevilla.

Eduardo García Jiménez (egarji@us.es).Es Profesor Titular del Departamento de Didáctica y Organización Escolar y Métodos de Investigación y Diagnóstico en Educación. Es miembro del grupo de investigación Métodos de Investigación y Diagnóstico en Orientación, de la Universidad de Sevilla. Su trayectoria profesional se halla vinculada a la medición y evaluación educativas, participando en distintas experiencias evaluativas. Dirección de contacto: Dpto. Departamento de Didáctica y Organización Escolar y Métodos de Investigación y Diagnóstico en Educación. Facultad de Ciencias de la Educación. C/ Camilo José Cela, s/n. 41018 Sevilla. 
Caballero Martínez, J., Fernández Camacho, C.R. y García Jiménez, E. (2003). Satisfacción de los secretarios de centros educativos. RELIEVE, v. 9, n. 2, p. 198-235.

http://www.uv.es/RELIEVE/v9n2/RELIEVEv9n2 7.htm

\section{ARTICLE RECORD / FICHA DEL ARTÍCULO}

\begin{tabular}{|c|c|}
\hline $\begin{array}{l}\text { Reference / } \\
\text { Referencia }\end{array}$ & $\begin{array}{l}\text { Caballero, Juan; Fernández Camacho, Carmen R. y García Jiménez, Eduardo (2003). Satisfacción de los se- } \\
\text { cretarios de centros educativos. Revista ELectrónica de Investigación y EValuación Educativa, v. 9, n. } 2 . \\
\text { http://www.uv.es/RELIEVE/v9n2/RELIEVEv9n2 7.htm. Consultado en (poner fecha). }\end{array}$ \\
\hline Title / Título & Satisfacción de los secretarios de centros educativos.[Secretaries of educational centers' satisfaction] \\
\hline Authors / Autores & Juan Caballero, Carmen R. Fernández Camacho y Eduardo García Jiménez \\
\hline $\begin{array}{l}\text { Review / } \\
\text { Revista }\end{array}$ & Revista ELectrónica de Investigación y EValuación Educativa (RELIEVE), v. 9, n. 2 \\
\hline ISSN & $1134-4032$ \\
\hline $\begin{array}{l}\text { Publication date / } \\
\text { Fecha publicación }\end{array}$ & 2003 (Reception Date: 2003 Sept 30; Approval Date: 2003 Nov. 13 Publication Date: 2003 Nov 26) \\
\hline $\begin{array}{l}\text { Abstract / } \\
\text { Resumen }\end{array}$ & 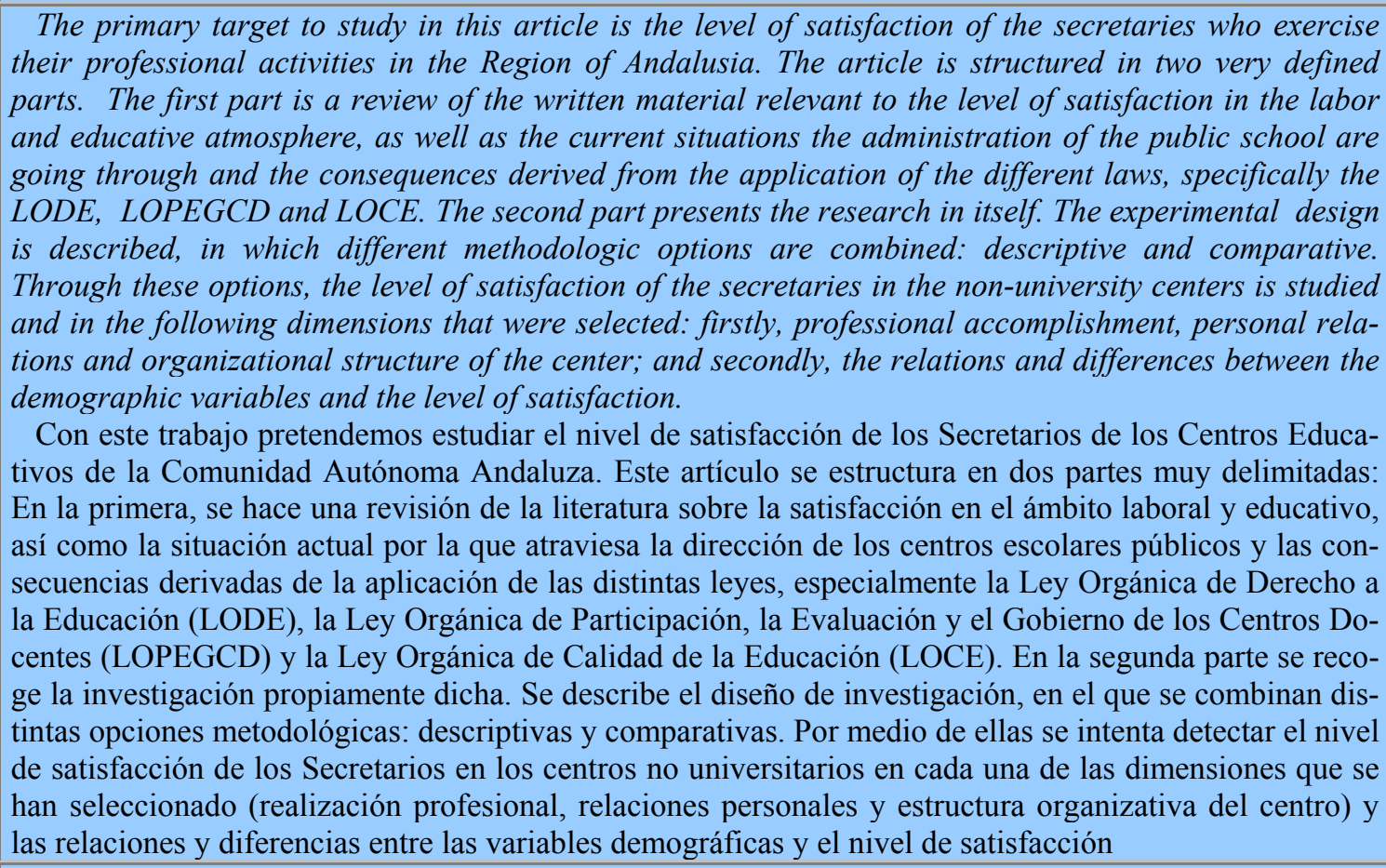 \\
\hline $\begin{array}{l}\text { Keywords } \\
\text { Descriptores }\end{array}$ & $\begin{array}{l}\text { Secretaries, satisfaction, organization of educational centers } \\
\text { Secretarios, satisfacción, organización de centros educativos }\end{array}$ \\
\hline $\begin{array}{l}\text { Institution / } \\
\text { Institución }\end{array}$ & Universidades de Granada y Sevilla (España) \\
\hline $\begin{array}{l}\text { Publication site / } \\
\text { Dirección }\end{array}$ & http://www.uv.es/RELIEVE \\
\hline $\begin{array}{l}\text { Language / Idio- } \\
\text { ma }\end{array}$ & Español (Title, abstract and keywords in english) \\
\hline
\end{tabular}

\section{Revista ELectrónica de Investigación y EValuación Educativa (RELIEVE)}

Electronic Journal of Educational Research, Assessment and Evaluation

[ ISSN: 1134-4032 ]

(C) Copyright, RELIEVE. Reproduction and distribution of this articles it is authorized if the content is no modified and their origin is indicated (RELIEVE Journal, volume, number and electronic address of the document).

(C) Copyright, RELIEVE. Se autoriza la reproducción y distribución de este artículo siempre que no se modifique el contenido y se indique su origen (RELIEVE, volumen, número y dirección electrónica del documento). 